\title{
La gens Aurelia en Hispania ulterior a través de las fuentes epigráficas
}

\author{
Henar Gallego franco *
}

\begin{abstract}
RESUMEN ABSTRACT
El presente trabajo evalúa la huella epigráfica del nomen Aurelius en las provincias hispanas Bética y Lusitania, determinando sus peculiaridades en el mapa gentilicio de ambas, así como su contribución al proceso romanizador y urbanizador de las mismas. Se estudian igualmente las caracteristicas onomásticas, socioeconómicas e ideológicas de sus portadores.

We analyze the epigraphical trace of the roman name Aurelius in Hispania Baetica and Lusitania, showing its peculiarities in the onomastic background of these provinces and its contribution to the romanization and urban process. Also, we study the onomastic, socioeconomic and ideological characteristics of the members of the gens Aurelia in these spanish provinces.
\end{abstract}

A través de las fuentes epigráficas del Occidente romano se constata la expansión sobresaliente de los llamados nomina imperiales en la onomástica personal, debido a la costumbre frecuente de los nuevos ciudadanos romanos provinciales de elegir como gentilicio que expresara su nuevo estatus jurídico aquél del emperador bajo cuyo reinado acceden al mismo. Esta práctica, sin embargo, es más popular en las provincias de romanización más tardía, como son las del área danubiana ${ }^{1}$. En Hispania,

Área de Historia Antigua. Universidad de Valladolid.

G. ALFódY, “Notes sur la relation entre le droit de cité et la nomenclature dans l'Empire romain", Latomus, XXV.1, 1966, 46; A. Mócsy, Die Bevölkerung von Pannonien bis zu den Markomannenkriegen, Budapest, 1959, 148. 
en cambio, el arranque temprano del proceso romanizador explica que el protagonismo de los nomina imperiales fuera claramente inferior al de otras regiones del Occidente Romano ${ }^{2}$.

El nomen Aurelius, de origen latino ${ }^{3}$, pertenece a este grupo de gentilicios imperiales. Su expansión en el Imperio hubo de recibir un impulso notable bajo los últimos Antoninos, en especial Marco Aurelio, y sobre todo bajo los Severos con el edicto de Caracalla del 212 d.C. ${ }^{4}$, si bien esta medida tuvo en las provincias hispanas un impacto menor que en otras zonas del Occidente Romano ${ }^{5}$. Ahora bien, un análisis detallado de la presencia de los Aurelii en las fuentes epigráficas de Hispania puede aportar nuevos datos. Atendiendo a este criterio, nos proponemos en el presente trabajo evaluar la huella epigráfica del nomen Aurelius en Hispania Baetica y Lusitania, determinando sus peculiaridades en el mapa gentilicio de estas provincias, así como su contribución al proceso romanizador y urbanizador ${ }^{6}$. Se trata, en última instancia, de una contribución al conocimiento del mapa onomástico de Hispania romana, en la idea de que cuanto más completo sea éste, más avanzaremos en el conocimiento de los rasgos propios de los procesos de romanización en las diferentes zonas peninsulares.

El gentilicio Aurelius alcanza una mayor difusión en Bética (60 individuos que en Lusitania (42 individuos), aunque ninguna de estas dos provincias se acerca a la notable incidencia de la gens en la Tarraconense ${ }^{\text {. }}$

2 Cfr. J.M. ABascal Palazón, los nombres personales en las inscripciones latinas de Hispania, Murcia, 1994, 28-30: en Hispania el nomen lulius es el único de tipo imperial que se encuentra entre los diez gentilicios más numerosos en estas provincias, y más distanciados se constatan ya los de Flavius y Aelius. G. AlfölDY, "Notes sur la relation entre le droit de cité et la nomenclature dans l'Empire romain», Latomus, XXV.1, 1966, 46-47 y H. GALSTERER, "Diritto latino e municipalizzazione nella Betica". Teoria y práctica del ordenamiento municipal en Hispania. Revisiones de Historia Antigua. II. Vitoria, 1996, 217, sobre la menor frecuencia con que en Hispania los nuevos ciudadanos toman el nombre del emperador.

3 W. SCHuLzE, Zur Geschichte Lateinischer Eigennamen, Berlin, 1966, 445, 468; PIR A 14281671.

4 Dion CASSIO, LXXVII, 9,20,27. En líneas generales, otorgaba la ciudadanía romana a todos los habitantes libres del Imperio que aún no disfrutaban de ella; en este sentido, la desigual presencia de Aurelii en las fuentes epigráficas de las distintas provincias del Imperio Occidental ha servido para especular sobre la importancia cuantitativa en las mismas de este sector de población de romanización deficiente, que accede a la ciudadanía gracias a la generosidad de Caracalla.

5 La Peninsula Ibérica vive un proceso romanizador temprano en el que ya se habia beneficiado ampliamente de los privilegios de ciudadania, especialmente gracias a la concesión del ius Latii por el emperador Vespasiano, cfr. Plinio, Nat. Hist., III, 30.

6 Este trabajo completa asi el estudio iniciado en $\mathrm{H}$. Gallego Franco, "Los Aurelii en la Hispania Tarraconense. Un estudio de las fuentes epigráficas", HAnt, XXIV, 2000, en prensa.

7 Hemos recogido cientocuatro individuos diferentes portadores del gentilicio Aurelius en Tarraconense, frente a cuarenta y dos en Lusitania y sesenta en Bética, recuento en el que excluímos a aquéllos que conocemos sólo por una filiación. 
Desde el punto de vista onomástico los Aurelii de Bética y Lusitania constituyen un grupo muy homogéneo. En general, son portadores de una antroponimia muy latinizada, con escasas pervivencias de onomástica indígena, cuyos esquemas se ajustan a los propios de los ciudadanos romanos. Así, las mujeres acompañan el gentilicio de un cognomen, mientras que entre los varones los esquemas de duo nomina predominan sobre los de tria nomina, aunque éstos últimos alcanzan en ambas provincias una incidencia notable, de al menos una tercera parte de los testimonios masculinos recogidos ${ }^{8}$. Atendiendo a su cronología, los tria nomina béticos y lusitanos manifiestan una sólida presencia ya en un período temprano (siglo I y primera mitad del siglo $॥$ ) ${ }^{9}$, aunque su número aumenta sensiblemente en la etapa siguiente, de finales del siglo || y siglo III d.C. ${ }^{10}$. Los portadores de praenomen son individuos de condición socioeconómica variada, desde libertos, individuos modestos, militares y veteranos,

8 En Lusitania los tria nomina alcanzan entre los varones una presencia del $35 \%$, mientras en la Bética su importancia aumenta hasta un $40 \%$. La incidencia de los tria nomina, en cambio, es algo más baja en la Tarraconense, donde suponen un $30 \%$ de los testimonios onomásticos masculinos.

9 Un tercio $(35 \%)$ de los tria nomina constatados en nuestras provincias se ubican cronológicamente en este período. En Bética contamos con AE 1980, 562, M. Aurelius M.f. Abbicus, miles legionis $X$ a mediados del siglo I en un documento hallado cerca de Nertobriga; CIL II(2).7, 207, $L$. Aurelius Lucanus, cerca de Sacili, a finales del siglo 1; AE 1965, 56, C. Aurelius Crito, en Malaca, a finales del siglo I, en una inscripción monumental en el teatro; AA9, 151, T. Aurelius Faustus, siglo Ii, cerca de Nertobriga, donde consagra a los Augusti Lares, una advocación próxima al culto imperial; CIL II(2).5, 733, L. Aurelius Capratinus, un notable de Aratispi a mediados del siglo I;; AAN̄ 105, M. Aurelius L.f. [--] en Hispalis, de la segunda mitad del siglo I. En Lusitania tenemos a DE 236, M. Aurelius C.f., Ilvir, flamen y praefectus fabrum en Pax lulia en el siglo 1; DE 445, los hermanos L. Aurelius M.f. Flaus y P. Aurelius Niger en Vila Vicosa, también en el siglo I; CIL II 203, M. Aurelius M.f. Marinus en Olisipo, del siglo I o comienzos del $\|$ d.C.

10 Los esquemas de tria nomina suponen en este período algo más de la mitad $(52 \%)$ del total de los registrados en ambas provincias. De finales del siglo II o principios del siglo III d.C. parecen ser, en Lusitania, DE 426, G. Aurelius Victorinus en Ebora; RE 31, L. Aurelius Rufus y RE 44, $M$. Aurelius Laberianus y su hijo $M$. Aurelius Avitus, en Conimbriga; AE 1961, 48, $M$. Aurelius Fili--J en Emerita, quizá un liberto imperial; En Bética, AAÑ 311, $M$. Aurelius (-) y su hijo $M$. Aurelius Nympho en Ilipa, familia relacionada con el comercio de aceite; CIL II 1291, G. Aurelius Ampliatus en Salpensa; CIL II 6338D, M. Aurelius Castor en Nabrissa; AAÑ 267, M. Aurelius Cemerus en Arva; CIL II(2).7, 422, M. Aurelius Marcellinus en Corduba; Ya en el siglo III d.C. contamos con CIL II(2).5, 375, M. Aurelius Achaicus en Iponoba y CIL II(2).5, 860, L. Aurelius Thebais en Teba del Condado (Málaga), individuos de posible origen servil como portadores de cognomina griegos; CIL II(2).7, 127A, M. Aurelius Valens, veteranus de la classis praetoria Severiana Ravennas cerca de Obulco; CIL II(2).7, 259, M. Aurelius Alexander, caballero, procurator Augustorum y agens vices praesidis quizá en época de Galieno. Hemos de considerar que algunos de los tria nomina recogidos (13\%) son de datación incierta: TR 37-39, L. Aurelius Ger(), propietario de figlina en un epigrafe oleario, y $\mathrm{AE} 1988,741, M$. Aurelius $V()$, en una plaqueta rectangular de plomo, ambos procedentes de la zona de influencia de Astigi, en la Bética; DE 251, G. Aurelius (-), patrono de un liberto en Pax Iulia, y CIL II 929, M. Aurelius [--], en un fragmento funerario de Caesarobriga, ambas en Lusitania. 
hasta altos cargos de la administración municipal e imperial ${ }^{11}$. El praenomen más frecuente en el grupo gentilicio es el de $M$ (arcus), especialmente propio de la onomástica imperial de los últimos Antoninos y Severos (Caracalla). Los M. Aurelii, de hecho, se concentran en las fuentes epigráficas béticas y lusitanas en la segunda mitad del siglo ॥ y primera del siglo III d.C. ${ }^{12}$, lo que no excluye la existencia de algunos testimonios excepcionalmente tempranos vinculados a élites sociales ${ }^{13}$. En menor medida encontramos a los $L$. Aurelii ${ }^{14}, G / C$. Aurelii ${ }^{15}, P$. Aurelii ${ }^{16}$ y $T$. Aurelii ${ }^{17}$, cuyos praenomina se constatan ya en el siglo I d.C., aunque luego contemos también con testimonios posteriores, y entre los que son frecuentes los individuos de posición socioeconómica destacada.

Apenas contamos con excepciones a estos esquemas, salvo por un grupo exiguo de casos en los que el gentilicio Aurelius no va acompañado

11 En este aspecto, el comportamiento de los tria nomina en Hispania Tarraconense es distinto, ya que se concentran casi exclusivamente en un período avanzado, desde finales del siglo ॥ d.C. en adelante, y son propios de individuos que manifiestan un estatus socioeconómico privilegiado.

12 En Bética, AAÑ 105, M. Aurelius L.f. [-l, en Hispalis; AE 1988, 741, M. Aurelius V() en el territorio de Astigi; AAÑ 311, M. Aurelius (-) y su hijo M. Aurelius Nympho en Ilipa; CIL II 6338D, M. Aurelius Castor en Nabrissa; AAÑ 267, M. Aurelius Cemerus en el territorio de Arva; CIL II(2).7, 422, $M$. Aurelius Marcellinus en Corduba; CIL II(2).7, 127A, M. Aurelius Valens en el territorio de Obulco; CIL II(2).5, 375, M. Aurelius Achaicus en Iponoba; CIL II(2).7, 259, M. Aurelius Alexander, procurator Augustorum y agens vices praesidis en Corduba. En Lusitania, CIL II 929, $M$. Aurelius [-j en Caesarobriga; RE 44, M. Aurelius Laberianus y M. Aurelius Avitus en Conimbriga; AE 1961, 48. $M$. Aurelius Fili ---] en Emerita. Se trata, como se puede apreciar, de individuos de condición socioeconómica variada: un equestre, varios ciudadanos romanos entre los que destaca un veterano militar y varios portadores de onomásticos griegos que quizá fueran individuos de origen servil.

${ }_{13}$ En la Bética, AE 1980,562, M. Aurelius M.f. Gal. Abbicus, miles legionis X en Jerez de los Caballeros (Badajoz), cerca de Nertobriga, en las primeras décadas del siglo I. En Lusitania, DE 236. M. Aurelius C.f. Gal., en Pax Iulia, IIvir, flamen y praefectus fabrum también a comienzos del siglo । d.C.; CIL II 203, M. Aurelius M.f. Gal. Marinus en Olisipo, del siglo I o principios del II d.C.

i4 Aparecen en ambas provincias en un momento temprano. Asi, CIL II(2).7, 207, L. Aurelius Lucanus en el territorio de Sacilis, de fin del siglo ।; DE 445, L. Aurelius L.f. Flaus, en Bencatel, cerca de Vila Viçosa, también en el siglo । d.C. A mediados del siglo ॥ les encontramos integrados en las familias notables del municipio bético de Aratispi, CIL II 2056, L. Aurelius Capratinus, y posiblemente en el negocio oleario, TR 37-39, L. Aurelius Ger(), en marcas del control de Astigi. Perduran todavía en el siglo III, RE 31, L. Aurelius Rufus en Conimbriga y CIL II(2).5, 860, L. Aurelius Thebais en Teba (Málaga), ambos individuos de posible origen servil.

15 En la Bética les constatamos en AE 1965, 56, C. Aurelius Crito, un notable local de Malaca en época flavia, y en CIL II 1291, G. Aurelius Ampliatus, en el territorio de Salpensa, a fines del siglo $\|$ o principios III d.C.; En Lusitania, DE 251, G. Aurelius (-), patrono de un liberto en Pax lulia, siglos II-11!; DE 426, G. Aurelius Victorinus, en Ebora, de finales del siglo $\|$ o principios del siglo III d.C.

${ }_{16}$ De 445, P. Aurelius Niger, hermano de L. Aurelius L.f. Flaus en Bencatel, Vila Viçosa, en el siglo id.C.

17 En Bética, EE IX, 151, T. Aurelius Faustus, que dedica a los Augusti Lares en Jerez de los Caballeros (Badajoz), cerca de Nertobriga, en el siglo ॥ d.C. El praenomen Q(uintus) podría verse en EEÑ 11, Q. Aurelius?, en Avila (Lusitania), de fin del siglo $\|$ o principio del 11, pero se trata de un documento muy deteriorado, de lectura dudosa, por lo que le dejamos al margen. 
de un cognomen, bien por una cronología especialmente temprana o tardía del testimonio epigráfico ${ }^{18}$, o por tratarse de portadores insertos en un ambiente de raíz indígena ${ }^{19}$. La tribu es un elemento que aparece raramente en el esquema antroponímico de los Aurelii béticos y lusitanos. Ahora bien, los pocos casos constatados corresponden a ciudadanos de origen autóctono, en ocasiones de estatus socioeconómico acomodado, inscritos en la tribu Galeria en las primeras etapas de la época altoimperial ${ }^{20}$. En cuanto a la mención de la origo ${ }^{21}$, se constata puntualmente en una etapa ya tardía, a partir del siglo III d.C., evidenciando un desplazamiento del portador cuya motivación no siempre es posible conocer pero responde en parte a motivos profesionales ${ }^{22}$. Ahora bien, otros indicadores onomásticos pueden

18 En Lusitania, DE 236, M. Aurelius C. $f$. Galeria en Pax lulia, de comienzos del siglo । d.C. En Bética, CIL $\|(2) .5,166$, Aurilius-sic, en un brazo de un crucifijo, de época ya muy tardía (siglos v-vi).

19 Así, en Lusitania JJX 40. Aurelius V/VCl f(ilius), familiar de Laboina Alais f(ilia), en Hinojosa (Salamanca); cfr. A. Holder, Alt- Celtischer Sprachschatz, vol.II, Graz, 1962, 113-115 (Lab-); Ibidem, I, 74 (Alanis como filiación); ZZ 2, Aurelius, en el mismo lugar. En la Tarraconense, en cambio, estos esquemas de nombre único de tradición indigena son algo más numerosos, cfr. U. Espinosa, Epigratia de la Rioja, Logroño, 1986, 70, Aurelia Lesuridantaris f(ilia) en Munilla (Logroño); G. Fatás/M.A. Martín Bueno, Epigrafía romana de Zaragoza y su provincia, Zaragoza, 1977, 61, Aurelius, en Villaroya (Zaragoza), en un epigrafe ilegible de fuerte ambiente indigena; F. Diego Santos, Inscripciones de la provincia de León, León, 1983, 266, Aurelius, en Crémenes (León), hijo de -Jo? Flaccus Flacci f(ilius) vadiniensis (Ptolomeo 2,6,50, pueblo de los cántabros); AE 1977, 489, Aurelius Maximini f. en Escuadro (Zamora); A. Holder, Alt-Celtischer..., vol.II, 191 (Lesuridantaris). Es dudoso en estos casos que los portadores gocen de la ciudadanía romana, a pesar de usar un gentilicio.

20 En Bética, AE 1980, 562, $M$. Aurelius $M$. $f$. Galeria Abbicus, miles de la legio $X$ en Jerez de los Caballeros (Badajoz); AE 1965, 56, C. Aurelius Galeria Crito, en Malaca, seguramente un notable municipal, dedicante (sua pecunia) de una inscripción monumental en el teatro; Los restantes testimonios proceden de Lusitania: DE 236, M. Aurelius C. f. Galeria, un notable de Pax lulia honrado con una estatua por los habitantes de la ciudad; CIL II 203, M. Aurelius M. f. Galeria Marinus, en Olisipo.

${ }_{21}$ En dos testimonios béticos, JJO 453, Aurelia Leucothoe, patriciensis, en Tucci, y CIL II(2).5,375, M. Aurelius Achaicus, astigitanus?, en el territorio de lponoba, dudamos que la mención de la origo exprese realmente el lugar de procedencia de ambos individuos. Los cognomina griegos Leucothoe y Achaicus hacen sospechar que se trate de dos libertos, y si es asi, hemos de tener en cuenta que los libertos llevaban la origo de sus patronos, cfr. Digesto, L, 1,6,3; J. Mangas, "Derecho latino y municipalización en la Meseta Superior", Teoria y práctica del ordenamiento municipal en Hispania, Revisiones de Historia Antigua, II, Vitoria, 1996, 236.

${ }_{22}$ En Lusitania, AE 1961, 48, M. Aurelius Filil--], residente en Rorna, quizá un liberto imperial, se halla en Emerita a finales del siglo $\|$ o siglo II d.C., donde dedica a la Dea Invicta Caelestis Nemesis; RE 31, cenotafio a $L$. Aurelius Rufus, natural de Conimbriga,cuyos restos descansan en Emerita, donde quizá fue para desempeñar algún cargo u oficio. En Bética, CIL II(2).7, 127A, el veterano $M$. Aurelius Capitolini $f$. Valens, ex gregalis classis, natural de Cibalis (Pannonia Inferior) aparece en un diploma militar de Higuera de Calatrava (Jaén) en el territorio de Obulco, del 225 d.C.: CIL II(2).5, 375, M. Aurelius Achaicus, astigitanus? en Iponoba en el siglo III; MG P.248, Aurelius lulianus, natural de Africa fallece en Malaca en el siglo IV d.C., donde posiblemente se vinculara a actividades comerciantes; CCG P. 455, Aurelius Felix Ingenuus, carteiensis y civis romanus fallece en Gades ya a finales del siglo iv o comienzos del siglo V. Por tanto los motivos de estos desplazamientos parecen ser principalmente profesionales. 
evidenciar también individuos de procedencia extranjera en el grupo gentilicio, como la presencia de cognomina griegos ${ }^{23}$.

Aunque la mayor parte de los cognomina ${ }^{24}$ que acompañan al gentilicio son latinos, esta presencia es superior en Lusitania (79\%), ya que en Bética su incidencia $(57 \%)$ se ve amortiguada por la notable constatación de onomásticos grecoorientales. Los cognomina latinos presentan un carácter variado y ninguno de ellos se repite en un número realmente significativo de individuos ${ }^{25}$. Como excepción, contamos con algunos casos en los que el gentilicio se acompaña de dos cognomina latinos, Aurelia Avita Restituta y Aurelius Felix Ingenuus ${ }^{26}$, o bien de un segundo gentilicio

23 Algunos pueden responder a una procedencia oriental de individuo o su familia. Asi, en Lusitania, AE 1972, 237, Aurelia Sotira y su esposo Aurelius Donatus, posiblemente miembros de una comunidad de comerciantes dálmatas en Emerita; CIL II 536, Aurelius Dorus, unido a Atilia Nicopolis también en Emerita, y que podrian igualmente formar parte de una comunidad de $\mathrm{Co}$ merciantes; en Bética, AE 1965, 56, C. Aurelius Galeria (tribu) Crito en Malaca, seguramente un notable local; TR 50-51, Aurelii Heraclae, padre e hijo, miembros de una importante familia de propietarios de varias figlinae, en la zona de Sevilla y Córdoba; AE 1984, 503, Aurelius Polyticus, dedicante de Némesis en Italica; CIL II 5521, Aurelius Stephanus, sacerdos Matris Deum en Corduba; CIL II(2).7,259, M. Aurelius Alexander, procurator augustorum y agens vices praesidis en Corduba.

${ }^{24}$ En algunos casos el cognomen se ha omitido, como en las filiaciones: AAÑ 105, $L$ Aurelius; CIL II 969, M. Aurelius; AAÑ 311, M. Aurelius, una filiación uxoria, todas ellas en Bética, y en Lusitania DE 445, L. Aurelius; CIL II 203, M. Aurelius; AE 1980, 562, M. Aurelius; también es el caso de las menciones en genitivo de patronos de libertos: DE 251, G. Aurelius en Lusitania. En otros casos el cognomen simplemente se ha perdido por deterioro del documento epigráficos: asi, en Bética, CIL II 5528, Aurelia [--]; AAÑ 105, M. Aurelius L.t. [-]; MMR P.254, M. Aurelius Capitonis f. [--]; y en Lusitania, ILER 5668, Aurelia [--]; DE 251, Aurelius [--]; DE 373, Aurelius [-]; EEÑ 11, Q. Aurelius [-]; CIL. II 929, M. Aurelius [-]

25 Excepto Rufus y su derivado Rufinus, de los que tenemos cinco testimonios en Lusitania, especialmente en las últimas décadas del siglo $\|$ y primer tercio del siglo II, todos ellos individuos de carácter modesto o de origen servil: CIL II 368, Aurelius Rufinus en Aeminium, RE 46, Aurelius Rufus en Conimbriga, RE 31, L. Aurelius Rufus también en Conimbriga, posiblemente los tres descendientes de libertos; EE VIII, 26. Aurelius Rufus, tabularius rationis patrimonii provinciae, probablemente un liberto imperial en Emerita; TC nota 30, Aurelius Rufus en Cárquere (Viseu, Portugal). I. Kajanto. The Latin Cognomina, Helsinki, 1965, 27, 28, 229 (Rufinus), 26, 27, 30, 64, $65,121,134,229$ (Rufus). Precisamente este es uno de los cognomina latinos más populares en Hispania romana, cfr. J.M. Abascal Palazón, Los nombres personales en las inscripciones latinas de Hispania, Murcia, 1994, 31.

${ }_{26}$ RE 45, en Conimbriga a fin del siglo I o comienzos del II; CCG P. 455, en Gades a finales del siglo Iv o principios del siglo $\vee$ d.C. I. Kajanto, The Latin..., 18, 79, 80, 134, 304 (Avitus), 356 (Restitutus/a), 13, 22, 26, 29, 30, 57, 71, 72bis, 73, 134, 272 (Felix), 314 (Ingenuus). En el primer caso, procedente de Lusitania, este tipo de polinomina puede ser un rasgo de latinización progresiva en un medio indígena, y de hecho Avita puede tener una raíz celta, cfr. A. Holder, AltCeltischer Sprachschatz, vol.I, Graz, 1961, 315 y RE 2, nota 12 y 13. En el segundo caso, procedente de Bética, parece señalar un estatus socioeconómico privilegiado, al que apunta también la calificación de carteiensis y civis romanus, que se da su portador. Cronológicamente los dos testimonios pertenecen a períodos muy diferentes, ya que el de Lusitania es de época altoimperial y el de Bética de la Antigüedad tardía. 
que actúa a manera de cognomen ${ }^{27}$ : Aurelia Flavia, Aurelia Licinia Florida, Aurelia Vibia Sabina, Aurelius Caecilius en Lusitania ${ }^{28}$, y dos Aurelii lulii en Bética ${ }^{29}$. Los antropónimos griegos, aunque minoritarios, gozan de cierta entidad entre los Aurelii ulteriores, especialmente en Bética, donde suponen una tercera parte de los cognomina constatados ${ }^{30}$. Los testimonios más tempranos son béticos, del siglo II d.C., pero se hacen más frecuentes desde época Severa. En ambas provincias los portadores son especialmente varones, ubicados en centros urbanos importantes, como Emerita, Aeminium, Conimbriga y Myrtilis en Lusitania, y Tucci, Italica, Hispalis, llipa, Corduba, Iponoba, Malaca, Sabora y Teba del Condado (Málaga) ${ }^{31}$ en Bética. Entre ellos encontramos un núcleo de libertos privados béticos ${ }^{32}$. Sin embargo, habida cuenta de la probada relación entre la onomástica griega y un origen servil del individuo ${ }^{33}$, podemos suponer la categoria de libertos para otros Aurelii portadores de cognomina griegos en nuestras provincias ${ }^{34}$. En este

${ }_{27}$ Este hecho no es infrecuente en la onomástica personal del Occidente Romano. Podría responder a la existencia de lazos familiares entre ambos grupos gentilicios, pero la falta de información sobre el entorno familiar de los portadores no permite comprobar este punto.

${ }_{28}$ CIL II 5323, Aurelia Flavia en Talavera de la Reina (Toledo); ILER 3341, Aurelius Caecilius en Cáceres; Los casos de Aurelia Licinia Florida (MGI 40, sarcófago paleocristiano de Emerita) y Aurelia Vibia Sabina (DE 497, dueña de esclavos en S. Miguel da Mota, Terena, Portugal) expresan además una polinomia acorde con una acomodada posición socioeconómica; $W$. Schuize, Zur Geschichte Lateinischer Eigennamen, Berlin, 1966, 167 (Flavius), 75, 454, 579 (Caecilius), $108,142,191,359,516$ (Licinius), 102, 425 (Vibius)

29 RL 27, Aurelius lulius, miles en Abla (Almeria); CG 36, 37, Aurelius lulius, agens vices praesidis y curator reipublicae Italicensium a finales del siglo ill d.C. en Italica. H. Solin/O. Salomies, Repertorium nominum gentilium et cognominum Latinorum, Hildesheim/New York/Zürich. 1988, 98 (lulius).

30 Mientras en Lusitania suponen un $15 \%$, en Bética los cognomina griegos ascienden al $35 \%$ del total de los testimonios recogidos. Esta incidencia es superior a la constatada en la provincia Tarraconense, donde los antropónimos griegos se sitúan en torno al $20 \%$.

31 Debió existir una ciudad antigua, de nombre desconocido, en esta zona, cfr. CIL II(2),5, pág. 237.

32 CG 90. Aurelia Afrodisia y su contubernalis Aurelius Myrismus en Italica a finales del siglo $\mid$ o comienzos del siglo III; CIL II 1426, Aurelius Euhemerus en Teba del Condado (Málaga), en el siglo ॥ d.C. Cfr. H. Solin, Griech Personennamen in Rom, Berlin, 1982, 315, 1337 (Aphrodisia), 1153 (Myrismus), 793, 1361, (Euhemer, Euhemera).

${ }_{33}$ H. Solin, Beitrage zur kenntnis der Griechischen Personennamen in Rom, Helsinki, 1971, 159. Cfr. para Hispania, A. Lozano, "La transmisión de los antropónimos griegos en la epigrafía latina de Hispania", Actas del $V$ Coloquio sobre lenguas y culturas prerromanas de la Peninsula Ibérica, Noviembre, 1989, Salamanca, 1993, 361-409.

34 Especialmente en Bética, donde constatamos AE 1983, $525=\mathrm{CIL}$ II(2) 5,889 , Aurelia Euprosine en Sabora a finales del siglo । o comienzos del siglo $\|$ d.C.; JJO 453, Aurelia Leucothoe en Tucci a comienzos del siglo "; AAÑ 53, Aurelius Hermes en Hispalis de mediados del siglo $\|$ o comienzos del siglo III d.C.; ZJ 1, Aurelius? Musicus en Italica a comienzos del siglo III d.C.; CIL II (2).5,860/861, L. Aurelius Thebais y Aurelia Agatho en Teba del Condado (Málaga) a comienzos del siglo III; CIL II (2).5,375, M. Aurelius Achaicus en Iponoba en el siglo III d.C.; En Lusitania contamos con AE 1972, 237, Aurelia Sotira en Emerita a comienzos del siglo III d.C.; CIL II 368, Aurelius Musaeus en Aeminium a finales del siglo Il o comienzos del siglo III d.C.; AE 1986, $277=$ AAO 37. Aurelius Asclepiades en Myrtilis a mediados del siglo ॥l d.C. Cfr. H. Solin, Griech personennamen..., 
sentido, parece por tanto que la onomástica griega en la gens Aurelia de Bética y Lusitania a menudo es distintivo de un origen servil del individuo, pero no exclusivamente, ya que en algunos casos puede también indicar una veta greco-oriental de la familia de éste ${ }^{35}$. En cambio, los antropónimos indigenas encuentran poca acogida entre los Aurelii béticos y lusitanos ${ }^{36}$, aunque algunos de sus portadores en Bética participan de un excelente nivel socioeconómico, como Aurelius Manus, un comerciante adinerado en Arva.

Finalmente, en la Bética la huella onomástica de la gens Aurelia se presenta también bajo la forma de cognomina derivados ${ }^{37}$, o través de la constatación de Aurelius como segundo gentilicio, vinculado especialmente con la gens Vibia ${ }^{38}$. Tanto en una como en otra circunstancia los testi-

428, 1340 (Euphrosyne), 499 (Leucon; Leucothoe no está constatado en Roma), 342, 1361 (Hermes), 417 (Sotira), 389 (Musaeus), 356, 1358 (Asclepiades), 1023 (Musicus), 576, 1312 (Thebais), 717 (Agatho), 571 (Achaicus). A. Lozano Velilla, Die griechischen Personennamen auf der iberischen Halbinsel, Heidelberg, 1998, 126 (Leucothoe).

35 Puede ser el caso en Lusitania de CIL II 536, Aurelius Dorus, unido a Atilia Nicopolis y ambos portadores de cognomina griegos en Emerita a finales del siglo $\|$ o principios del siglo $\| 1$ d.C.; en Bética, los de AE 1965, 56, C. Aurelius Galeria (tribu) Crito en Malaca, de finales del siglo I d.C., seguramente un notable local; TR 50-51, Aurelii Heraclae, padre e hijo, miembros de una importante familia de propietarios de varias figlinae, antes de propiedad imperial, en la zona de Sevilia y Córdoba en época postseveriana; AE 1984, 503, Aurelius Polyticus, dedicante de Némesis en Italica a comienzos del siglo III; CIL II 5521, Aurelius Stephanus, sacerdos Matris Deum en Corduba también a comienzos del siglo II d.C.; AE 1961, 48, M. Aurelius Fili[-] que dedica a la Dea Invicta Caelestis Nemesis en Emerita a finales del siglo 11 o comienzos del siglo III d.C.; CIL II(2).7,259, M. Aurelius Alexander, procurator augustorum y agens vices praesidis en Corduba a mediados del siglo III d.C.; cfr. H. Solin, Griech.., 472 (Dorus), 628 (Nicopolis), 482 (Heracla), 252, 1342 (Criton), 1011 (Politicus), 1182, 1368 (Stephanus), 186, 1355, 1356 (Alexander). El cognomen incompleto Fili[--] seguramente era un antropónimo griego, cfr. $\mathrm{H}$. Solin, Griech..., 1561 (Phili-). Algunos de ellos (Dorus, Polyticus, Stephanus), es posible que aunaran una procedencia greco-oriental con un origen servil.

${ }_{36}$ No contamos con cognomina indígenas entre los Aurelii lusitanos; En la Bética, AE 1980, 562, M. Aurelius M.f. Abbicus, miles legionis $X$ en Jerez de los Caballeros (Badajoz), en las primeras décadas del siglo I d.C.; ILER 3333, Aurelia Arconis f. Annia, en Messangil, en la Sierra de Serpa, cerca de la frontera con la Lusitania, en el siglo ॥ d.C.; AAÑ 267, M. Aurelius Cemerus, en Villanueva del Rio (Sevilla), territorio del municipio de Anva, a finales del siglo II o principios del III; AAÑ 222, Aurelius Manus, también en Arva, siglo III d.C.; ZJ 1, Aurelius Ugaiddillus, quizá un liberto, ya que su hermano Musicus es portador de un cognomen griego, en Italica a comienzos del siglo III d.C.; Cfr. A. Holder, Alt-Celtischer Sprachschatz, voł.III, Graz, 1962, 1198 (Cemerus), 471 472 (Abb-); A. Holder, Alt-Celtischer Sprachschatz, vol.I, Graz, 1961, 184 (Arco), 156-157 (Anni-); M.L. Albertos, La onomástica personal primitiva de Hispania Tarraconense y Bética, Salamanca, 1966, 26 (Anna). A. Caballos, "Varia funeraria italicense", Habis, 25, 1994, 234, considera Ugaiddillus la latinización de un cognomen turdetano. Cfr. P. Piernavieja, "Denudator gimnasi v.s. arescu', Homenaje a García y Bellido. V (Anejos de Gerión. 1), 1988, 362, sobre el origen indígena de Manus.

37 En concreto Aurelianus, cfr. I. Kajanto, The Latin Cognomina.., 20, 32, 35 bis, 141.

38 Los Vibii constituyen un grupo gentilicio bien constatado en Bética: Teba del Condado (Málaga), Iluro, Cartima, Corduba, Iponoba, Barbesula, Urso, Hispalis, Italica, Astigi, Ostippo, 
monios recaen en ciudadanos romanos de núcleos privilegiados y pertenecientes a élites sociales ${ }^{39}$. En conclusión, los integrantes de la gens Aurelia en Hispania Bética y Lusitania presentan una onomástica personal muy homogénea, altamente romanizada y latinizada. Resultan muy generalizados los esquemas clásicos ciudadanos de duo y tria nomina, éstos últimos portados por individuos de condición socioeconómica variada. La pervivencia de rasgos antroponímicos prerromanos es meramente anecdótica, aunque puntualmente puede cobrar la forma de cognomina indígenas ${ }^{40}$. La onomástica griega se asocia en general a varones ubicados en ámbitos urbanos, resultando especialmente vigorosa en Bética, y su presencia responde a un origen greco-oriental del portador o de su entorno familiar, o, más frecuentemente, a una ascendencia servil de éste. Finalmente, la aparición de otros elementos onomásticos, como la tribu y origo, resulta excepcional. Ahora bien, mientras que la tribu se expresa en el esquema onomástico de ciudadanos de origen hispanorromano, la origo viene a explicitar un desplazamiento del individuo que la menciona, y que suele ser un extranjero en nuestras provincias.

Arucci, Gades, Jerez de los Caballeros (Badajoz). Sus miembros a menudo forman parte de las aristocracias municipales y los evergetes locales, cfr. CIL II 965, 966, 967, 1157, 1403, 1424, 1466, 1497, 1510, 1600, 1912, 1938, 1952, 1953, 1958, 2216, 5397, 6277c; AAÑ 37, 93.

39 $\operatorname{AE} 1982,522=$ CIL $\|(2) .7,102$, Vibia Aurelia, en Berlanga (Badajoz), en el territorio del municipio flavio de Regina, a finales del siglo $\|$ o comienzos del siglo $\|$ d.C.; CIL $\| 1181=$ AAÑ 24, en Hispalis, donde recibe honores, con el beneplácito del ordo de la ciudad, el caballero $L$. Vibius L.f. Gal. Tuscus Aurelius Rufinus, praefectus cohortis primae Ausetanorum?, quizá en el siglo ॥ d.C.; CIL II 1945, L. Munius Quir. Aurelianus, IIvir, que a fines del siglo I rinde honores al emperador Domiciano en Iluro (Alora, Málaga), cfr. A. Tovar, Iberische Landeskunde. Die Wölker und die Städte des antiken Hispanien. II. Baetica, Baden-Baden, 1974, 132-133.

40 En la Tarraconense la acogida de los cognomina indigenas entre los Aurelii también es muy reducida: CIL II(2).14.1, 260, G. Aurelius Reburinus en Viver (Castellón); ILER 4057, Aurelius Tannepaeseris, Puebla de Castro (Huesca); A. Llanos Ortiz de Landazuri, Carta arqueológica de Alava. I. Vitoria, 1987, 9013, Aurelia Flacci f(ilia) Boutia Attesuclon en Assa (Vitoria); F. Arias Vilas/P. Le Roux/A. Tranoy, Inscriptions romaines de la province de Lugo, Paris, 1979, 78, Aurelia Nantia, en Láncara (Lugo); A. Holder, Alt-Celtischer Sprachschatz, vol.I, Graz, 1961, 499 (Boutia); A. Holder, AltCeltischer Sprachschatz, vol.II, Graz, 1962, 684 (Nantia), 1088 (Reburinus), 1720 (Tannepaeseris). Sin embargo la influencia de la onomástica indígena se amplia con la mención de populi y gentilitates, que en cambio es inexistente en Bética y Lusitania. Ctr. la ya citada Aurelia Boutia Attesuclon; U. Espinosa, Epigrafía de la Rioja, Logroño, 1986, 70, Aurelia Lesuridantaris f. Caericiocon, en Munilla (Logroño); A. Rodríguez Colmenero, Galicia Meridional Romana, Deusto, 1977, 95, Aurelius Flaus, Tamacanus Tacamus, de la civitas Tamacanorum, del pueblo de los Tacami (valle de Verin), hallada en Sta. Eufemia de Ambia (Orense), cfr. A. Rodríguez Colmenero, Galicia Meridional Romana, Deusto, 1977, 367; Idem, Aquae Flaviae. I. Fontes Epigráficas de Gallaecia Meridional Interior, Chaves, 1987, $n{ }^{\circ} 65$; F. Diego Santos, Inscripciones de la provincia de León, León, 1983, 266, Aurelius, vadiniensis, como su padre, en Crémenes (León); sobre los cántabros vadinienses cfr. Ptolomeo 2,6,50; C. García Merino, Población y poblamiento en Hispania Romana. El conventus cluniensis, Valladolid, 1975, 29; M.C. González Rodriguez, Los astures y los cántabros vadinienses: problemas y perspectivas de análisis de las sociedades indigenas de Hispania indoeuropea, Vitoria, 1997. 
Desde el punto de vista social, las élites superiores aparecen representadas entre los Aurelii de Bética y Lusitania fundamentalmente por un grupo de caballeros, de origen extraprovincial, que ocupan altos cargos en la administración provincial bajoimperial. Así, en Bética, M. Aurelius Alexander, procurator augustorum y agens vices praesidis a mediados del siglo III, Aurelius lulius, agens vices praesidis y curator reipublicae Italicensium a finales del siglo III, y Aurelius Ursinus, curator reipublicae Italicensium en el mismo período ${ }^{41}$. En Lusitania es el caso de Aurelius Ursinus ${ }^{42}$, praeses de la provincia, quizá de época de Diocleciano. Son exponentes, en definitiva, de la promoción de nuevas familias aristocráticas a partir de la Constitutio Antoniniana y del protagonismo de los cuadros de caballeros en la administración bajoimperial ${ }^{43}$. Precisamente, desde este grupo emana una parte significativa del comportamiento evergético y público de la familia, en general reducido, en forma de dedicaciones honoríficas al emperador de turno ${ }^{44}$ o restauración de edificios públicos promovida desde la esfera

${ }^{41}$ CIL II(2).7, 259, vir egregius, quizá de época de Valeriano y Galieno; CG 36 y 37, vir perfectissimus, en el 276 d.C., de época de Floriano y Probo, cfr. A.H.M. Jones/J.R. Martindale/J. Morris, The Prosopography of the Later Empire, vol.I, Cambridge, 1971, 481; CG 36, vir egregius, época de Floriano. La presencia de estos curatores reipublicae refleja el aumento de intervencionismo estatal en la colonia de Italica a finales del siglo \#, cfr. G.P. BuRToN, “The Curator Rei Publicae: towards a Reappraisal», Chiron, 9, 1979, 465ss.; R. Duthor, “Curatores Reipublicae en Occident durant le Principat. Recherches sur l'apport des sources épigraphiques", Ancient Society, 10 (1979), 171ss; G. Camodeca, "Curatores rei publicae", ZPE, 35, 1979, 225-236; Idem, "Ricerche sui curatores rei publicae", ANRW, II.13, 1980, 453-534; M. SARTORI, "Osservazioni sul ruolo del curator rei publicae", Athenaeum, 67/1-II, 1989, 5-20.

${ }_{42}$ De 5, vir perfectissimus; A.H.M. Jones/J.R. Martindale/J. Morris, The Prosopography..., I, 987.

43 Estos cuadros dirigentes muestran igualmente una alta representatividad entre los Aurelii de la Tarraconense a través de las fuentes epigráficas: G. ALFölDY, Die romischen Inschriften von Tarraco, Tarragona, 1976, 89/90, M. Aurelius Valentinianus, vir clarissimus, praeses provinciae en 283 d.C.; PIR ${ }^{2}$ A 1623; A.H.M. Jones/J.R. Martindale/J. Morris, The Prosopography..., I, 937; G. Alföldy, Fasti Hispanienses, Wiesbaden, 1969, 304; CIL II(2).14.1, 789, Aurelius Flaminius Priscus, legatus iuridicus de la Tarraconense también a finales del siglo III d.C.; GA 154, Aurelius lanuarius, vir perfectissimus, procurator provinciae en la primera mitad del siglo II d.C.; H.G. Pflaum, Les carrières procuratoriennes équestres sous le Haut-Empire romain, vol.ll, Paris, 1960-1961, 893; G. ALFÖLDY, Die romischen.... 155, Aurelius Vincentius, vir perfectissimus, praeses provinciae en el siglo Iv d.C.; A.H.M. Jones/J.R. Martindale/J. Morris, The Prosopography..., 1, 966. A través de fuentes de diferente procedencia podemos ampliar la incidencia del gentilicio Aurelius en los altos cargos de la administración imperial tardía en Hispania, y en concreto en la Bética: A.H.M. Jones/J.R. Martindale/J. Morris. The Prosopography...,I, 31, Aurelius Agricolanus, vicarius Hispaniarum hacia el 298 d.C.; 757, M. Aurelius Consius Quartus, vicarius Hispaniarum a mediados del siglo IV d.C.; PIR ${ }^{2}$ A 1539; J.M. Ojeda Torres, El servicio administrativo imperial ecuestre en la Hispania Romana durante el Alto Imperio. l. Prosopografia, Kolaios. Publicaciones ocasionales. 2, Sevilla, 1993, n. ${ }^{\circ} 19, M$. Aurelius Tuesianus, vir egregius a ducenis de la Bética.

44 En la Bética, CIL (2).7, 259, M. Aurelius Alexander honra probablemente a los emperadores Valeriano y Galieno en Corduba; CG 36, Aurelius Ursinus, Aurelius lulius y la respublica Italicensium honran a Floriano; CG 37, Aurelius lulius y la respublica Italicensium al emperador Probo; DE 5, Aurelius Ursinus a Diocleciano en Ossonoba, Lusitania. 
gubernamental ${ }^{45}$. Igualmente, el ordo senatorial tiene en la familia una única representante, muy tardía, en la persona de la clarissima femina Aurelia Proba ${ }^{46}$, cuyo testimonio hallamos en Hispalis.

Ahora bien, algunos miembros de la gens alcanzaron una notable promoción socioeconómica en el siglo "I y primeras décadas del siglo II d.C., como evidencia su posición de patronos de libertos y dueños de esclavos, entre los que destacan especialmente tres mujeres del siglo II d.C.: Aurelia Fesenia-sic, patrona de cuatro libertos en Teba (Málaga), Aurelia Materna, patrona de otro en Conimbriga, y Aurelia Vibia Sabina, dueña de un servus marmorarius también en Lusitania ${ }^{47}$. Igualmente, existieron dueños y patronos entre los Aurelii de Italica y Pax lulia ${ }^{48}$, como prueba la presencia de libertos privados. Además, los onomásticos griegos, ya analizados ${ }^{49}$, nos inducen a sospechar la existencia de patronos y dueños de la gens Aurelia en varios núcleos urbanos de Lusitania ${ }^{50}$, y sobre todo de la Bética, en las provincias de Málaga, Jaén, Córdoba y Sevilla ${ }^{51}$, concentrados especialmente en la segunda mitad del siglo II y primeras décadas del siglo III d.C. En algún caso son los lazos familiares los que parecen apuntar al origen servil de algunos Aurelii ${ }^{52}$. Es posible que la presencia de antropónimos

45 CIL II 191, Aurelius Firmus en Olisipo se encarga de la restauración de las Thermae Cassiorum ordenada por Numerius Albanus, vir clarissimus y praeses provinciae Lusitaniae en 336 d.C.; A.H.M. Jones/J.R. Martindale/J. Morris, The Prosopography...,I, 32.

46 AAÑ 142; A.H.M. Jones/J.R. Martindale/J. Morris, The Prosopography of the Later Empire, vol.II, Cambridge, 1980, 908.

47 CIL II(2).5, 855, patrona de los Aurelii Antullus, Cupitus, Germanus y Euhemerus; RE 46 , patrona de Aurelius Vernaclus y quizá de su hijo Aurelius Rufus; DE 497, dueña de Hermes, en S. Miguel da Mota (Terena, Portugal) en un santuario de Endovellicus.

48 CG 90, Aurelia Afrodisia y Aurelius Myrismus, dos libertos de Italica, de finales del siglo $\|$ o comienzos del siglo III. DE 251, Aurelius [--], que parece liberto de un G. Aurelius en Pax lulia.

49 Sabida es la relación que suele presentar la onomástica griega con un origen servil del individuo, cfr. H. Solin, Beitrage zur kenntnis der Griechischen Personennamen in Rom, Helsinki, $1971,159$.

50 CIL II 368, Aurelius Musaeus y su hijo Aurelius Rufinus en Aeminium, y CIL II 536, Aurelius Dorus, en Emerita, ambas de finales del siglo 11 o comienzos del siglo il d.C.; AE 1986, 277, Aurelius Asclepiades, en Myrtilis, de mediados del siglo III d.C.

51 En Málaga: AE 1983, $525=$ CIL II(2).5.889, Aurelia Euphrosine en Sabora, a finales del sigio 10 comienzos del siglo II d.C.; CIL II(2).5.861, Aurelia Agatho y CIL II(2).5,860, L. Aurelius Thebais, en Teba del Condado, a comienzo del siglo III. En Jaén: JJO $453=\mathrm{CIL}$ II(2).5, 102, Aurelia Leucothoe en Tucci, a comienzos del siglo II. En Córdoba: CIL II(2).5, 375, M. Aurelius Achaicus, en Iponoba; CIL II 5521, Aurelius Stephanus, sacerdos Matris Deum en Corduba, ambos en el siglo III. En Sevilla: AAÑ 53, Aurelius Hermes en Hispalis, bien a mediados del siglo II o comienzos del siglo III d.C.; AAÑ 311, M. Aurelius Nympho en llipa, de finales del siglo II o comienzos del siglo III; AE 1984, $503=$ CG 7, Aurelius Polyticus en Italica, a inicio del siglo III d.C.

52 En dos documentos de Conimbriga: RE 31, Aurelia Prisca y su hijo L. Aurelius Rufus portan el mismo gentilicio, lo que puede evidenciar que Prisca y su marido llevaban el mismo gentilicio, quizá porque habian sido esclavos de un mismo dueño; RE 46, donde Aurelius Rufus resulta ser hijo de dos libertos, Aurelius Vernaclus y Aemilia Fortunata. 
griegos en ausencia de un indicativo explícito sobre el origen servil del portador bien pueda obedecer al deseo de éste último de ocultar este particular en aras de una posible promoción social ${ }^{53}$. En todo caso, prevalecen en la gens Aurelia de Bética y Lusitania las relaciones de dependencia de ámbito privado. Mientras que entre los Aurelii de la Tarraconense destacaba en la esfera social de dependencia un núcleo de élite integrado por libertos imperiales, especialmente los altos cargos de la cuenca minera leonesa ${ }^{54}$, en la Bética y Lusitania atestiguamos sólo algún liberto imperial en Emerita, la capital lusitana ${ }^{55}$, ciudad de intensa actividad administrativa.

Por otro lado, determinadas actividades profesionales se revelan, a través de los testimonios epigráficos analizados, como fuente de bienestar económico para varios integrantes de nuestro grupo gentilicio. Varios de ellos aparecen implicados en la esfera de las actividades y relaciones comerciales, bien con Oriente, caso de la pareja formada por Aurelius Donatus y Aurelia Sotira en Emerita Augusta, o con el norte de Africa, y así la presencia del africano Aurelius Julianus en Malaca manifiesta la pervivencia de los lazos de intercambio con el otro lado del Estrecho todavía en época bajoimperial ${ }^{56}$. El comercio, en este caso de bestias para los espectáculos de masas, sirvió al bético Aurelius Manus, possessor leopar-

53 A. LOZANO, "La transmisión de los antropónimos griegos en la epigrafía latina de Hispania", Actas del $V$ Coloquio sobre lenguas y culturas prerromanas de la Península lbérica, Noviembre, 1989, Salamanca, 1993, 366-367, 369, señala que con relativa frecuencia no se menciona explícitamente el origen servil en los documentos epigráficos, precisamente por el deseo de los libertos de buena posición económica de aprovechar ésta para promocionarse socialmente. Cfr. J.M. Serrano Delgado, Status y promoción social de los libertos en Hispania romana, Sevilla, 1988.

54 Varios procuratores metallorum de los últimos Antoninos, como Aurelius Hermes, Aurelius Zoilus, M. Aurelius Eutyches y Aurelius Firmus: AE 1910, 3,4,6; AE 1910, 5; AE 1967, 230; AE 1910,2 ; AE 1966, 188, todas ellas dedicaciones de fuerte carácter oficial y próximas al culto imperial. Las tareas de explotación minera pueden explicar también la presencia de Aurelius Dionysius en Aquae Flaviae (CIL II 2474). Otro centro que aglutina a esta influyente élite servil es la capital, Tarraco, centro administrativo de primera magnitud, donde encontramos a $M$. Aurefius Successus (G.Alföldy, Die romischen..., 231), subprocurator $X X$ hereditatium en época Severa, y la familia integrada por Aurelius Marcianus, su esposa Aurelia Daphne y su hijo Aurelius Macedo (G. ALFoloy, Die romischen..., 246, quizá de finales del siglo $\|$ o siglo it d.C.).

5. EE VIII, 26, Aurelius Rufus, tabularius rationis patrimonii provinciae Lusitaniae, a quien pone el monumento funerario a finales del siglo II su hermano, Aurelius Festus, seguramente también un liberto imperial. También en Emerita, AE 1961, 48, M. Aurelius Filit-J, que dedica a Némesis en el anfiteatro, quizá sea liberto imperial, ya que su cognomen parece griego, como ya hemos indicado, y reside en la ciudad de Roma.

56 AE 1972, 237; J.F. RODRIGUEZ NEILA/F. Chaves TRISTAN, «Un monumento funerario procedente de Emerita", Habis, 4, 1973, 295-310, onomástica familiar de raices ilirias, quizá miembros de una colonia de comerciantes de Dalmacia en Emerita. Quizás también sea el caso de la pare. ja emeritense formada por Aurelius Dorus y Atilia Nicopolis (CIL II 536), cuyos cognomina griegos podrian apuntar a una procedencia oriental. Sobre Aurelius lulianus, P. RODRiciuzz OuIva, “Dos testimonios epigráficos de los contactos entre Malaca y los territorios norteafricanos", Mainake, IV-V. 1982-1983, 248 ss. 
dorum en Arva, para reunir una notable fortuna ${ }^{57}$. Otra importante fuente de recursos del grupo gentilicio en la Bética es la producción y comercio de aceite de oliva. Las marcas anfóricas halladas en suelo bético atestiguan propietarios de varias figlinae, como los poderosos Aurelii Heraclae, padre e hijo, en las provincias de Córdoba y Sevilla, y L. Aurelius Ger(-), en la zona de Astigi (Ecija, Sevilla) ${ }^{58}$. También en llipa (Alcalá del Río, Sevilla) los Aurelii, vinculados a los Marii, parecen implicados a la red económica de la producción olearia ${ }^{59}$. La epigrafía anfórica extrapeninsular confirma esta implicación de la gens Aurelia en el comercio de aceite bético, centrada especialmente en el siglo ॥ d.C., no solo como propietarios de figlinae, sino también como dueños de fundi o fincas productoras o como diffussores, mercatores o navicularii ${ }^{60}$. También las actividades artesanales fueron del interés de los Aurelii, tanto en Bética como en Lusitania, donde se destaca la persona de Aurelia Vibia Sabina, propietaria de un servus marmorarius, lo que apunta a que ella misma y su familia basaran parte de su economía en la explotación de canteras ${ }^{61}$.

57 P. Piernavieja, "Denudator gimnasi v.s. arescu”, Homenaje a Garcia y Bellido, $V$ (Anejos de Gerión, I), 1988, 359-379, se trata de un personaje adinerado que se dedicaba a la importación de animales salvajes con destino a las venationes y espectáculos de la Bética.

58 G. ChIC Garcia, Epigrafía Anfórica Bética, I, Sevilla, 1985, 7, 8, 50, 51, 60, 61, en marcas béticas quizá de época de Severo Alejandro, miembros de un clan poderoso, parece que estas figlinas cayeron en su poder después de ser propiedad imperial. G. Chic García, Epigrafía... I, 3739 , sin datación.

59 AAÑ $311=$ CIL II 1099, de finales del siglo II o principios del siglo $\|$ d. d., donde encontramos a $M$. Aurelius () y $M$. Aurelius Nympho, esposo e hijo respectivamente de Maria Q.t. Nymphe, emparentada, quizá a través de relaciones de dependencia dado su cognomen griego, con dos conocidas diffusores o transportistas de aceite, Maria Q. f. Fesia[na?] y Maria Q.f. Postumina (G. CHIC, Epigrafia Anfórica Bética. II, Sevilla, 1988, 34).

50 Propietarios de fundi: G. CHic, Epigrafía Anfórica Bética, 11.., 93.8, Aurelius Celer en un testimonio del Testaccio (Roma), fechado en 174 d.C. y procedente quizá de Corduba; 93.7, Aurelius Balbus, en un documento de Vienna (Francia) fechado a inicios del siglo II d.C. Diffussores: G. CHic, Epigrafía Anfórica Bética, II..., 13.2, los Aurelii aparecen como sociedad familiar en un documento hallado en Fos sur mer (Francia); 13.4 (= CIL XV 3748), M. Aurelius Sotat..., hallado en Testaccio (Roma), del periodo 145-161 d.C. y quizá procedente de Corduba; 13.3, M. Aurelius Pyrallus, documento hallado en Macon (Sâone-et-Loire. Francia) de comienzos dei siglo "l (120-125 d.C.), procedente de Hispalis; 13.6, Aurelius Vinitor, en Testaccio (Roma), fechada a mediados de siglo ॥; 13.5, T. Aurelius Speratus, en los Horti Tortolonia (Roma), de mediados del siglo II y procedente de Corduba.

51 Bética: CIL II(2).5, 1177, ex offi(cina) Aur(elii) Cari, en una cañería de plomo de la red municipal, en Astigi, siglo ॥ d.C.; CIL II(2).5, 332, Aurelius Carisius, nombre de artesano en unas losas reutilizadas en una necrópolis paleocristiana o visigoda de Igabrum. Lusitania: DE 497 , donde se apunta a su rango social elevado, evidenciado en su onomástica, tanto por la polinomia como por significativos paralelismos con Calpurnia Sabina (CIL II 112), senatorial de Ebora, o con mujeres de la familia imperial de los Antoninos, como Vibia Sabina, esposa de Hadriano, o Vibia Aurelia Sabina, hija de Marco Aurelio, lo que no implicaría un parentesco sino el seguimiento de una moda onomástica de la Corte. Cfr. J. AlARCAO, Portugal Romano, Lisboa $1974,130-131$. 
Finalmente, el ejército, como actividad profesional, tiene una incidencia muy reducida entre los Aurelii de nuestras provincias, donde realmente contamos tan solo con testimonios puntuales e inconexos en este ámbito procedentes de la Bética: un miles de la legio X Gemina ${ }^{62}$, un marinero veterano de la flota de Rávena ${ }^{63} \mathrm{y}$ un miles praetorianus ${ }^{64}$. En definitiva, el ámbito profesional de la gens Aurelia de Hispania Ulterior resulta más variado y rico en actividades que el de la Citerior o Tarraconense, donde la única profesión constatada explícitamente es el servicio en el ejército, de gran utilidad en torno a la capital provincial, Tarraco, centro administrativo

62 El testimonio de AE 1980,562, M. Aurelius M.t. Gal. Abbicus, miles legionis $X$, en Jerez de los Caballeros (Badajoz), en la zona bética limitrofe con Lusitania, pertenece a un período altoimperial muy incipiente, de principios del siglo I, momento en la legio X Gemina todavia se encuentra en suelo hispano antes de salir hacia Carnumtum (Pannonia) en el 63 d.C. Quizá haya que relacionar la presencia de este miles en la zona con la ruta de salida de los productos mineros por Lusitania hacia los puertos de la Bética. A partir de su participación en las Guerras Cántabras, las labores en Hispania de la legio $X$ Gemina se fueron diversificando desde las puramente propias de un ejército de conquista, -anexión de nuevos territorios y vigilancia de la población indígena recién sometida - hasta otras más propias de un ejército de ocupación, que se centran en la colaboración con el gobierno imperial provincial en las tareas administrativas y de explotación económica y de recursos, cfr. P. Le Roux, L'Armée romaine ef l'organisation des provinces iberiques d'Auguste a l'invasion de 409, París, 1982 , 122; F.J. SANCHEZ-PALENCIA, «El campamento romano de Valdemeda, Manzaneda (León). Ocupación militar y explotación aurifera en el Noroeste Peninsular", Numantia, II, 1986, 227. 234; G. Fabre/M. Mayer/l. Roda, “A propos su pont de Martorell: la participation à l'amégenemat su réssau routier de la Tarraconense Oriental sous Auguste", Epigraphie Hispanique, Paris, 1984, 283-284; J. Lostal Pros, Los milliarios de la provincia Tarraconense, Zaragoza, $1992,26-27$.

63 CIL II(2).7, 127A, M. Aurelius Capitolini $f$. Valens, natural de Cibalis en Pannonia Inferior, ex gregalis classis praetoriae Severianae Ravennatis, es decir, un veterano de esta flota, en un diploma militar hallado en Higuera de Calatrava (Jaén), en una villa del territorio de Obulco; tras su licenciatura, en 225 d.C., nuestro hombre se retiró a la Bética, cfr. González Román/P.A. Recio Veganzones, "Diploma militar de Higuera de Calatrava en la provincia de Jaén (Baetica)", Florentia lliberritana, 3, 1992, 249-258; C. GONZALEZ ROMAN, «Diploma militar de Higuera de Calatrava en la provincia de Jaén (Baetica). Nuevos fragmentos y reconstrucción del extrinsecus», Florentia lliberritana, 4-5, 1993-1994, 255; H. Gallego Franco, "Pannonios en Hispania Romana», HAnt, XXI, 1997, 354- 357.

64 AE 1965, 100= ILER $441=$ JJO $228=\mathrm{CIL} \mathrm{II(2).7,} \mathrm{33,} \mathrm{Aurelius} \mathrm{Marcellinus,} \mathrm{miles} \mathrm{cohortis}$ VIIII praetoriae en Iliturgi, muy cerca de la zona limitrofe con la Tarraconense, en la primera mitad del siglo III d.C. Mantenemos la lectura del epigrafe que hace CIL II (2), aunque en HEp5, 496 se lee Aurel(ianus) Marcellinus. Parece tratarse de una votiva, probablemente a lanus Augustus por su ubicación en el umbral de la Bética, puesta por un grupo de milites praetoriani de distintas unidades, de los que debía existir un campamento en lliturgi, y erigida quizá en relación con la provisión de la annona. También próximo al límite entre la Bética y la Tarraconense, en Abla (Almería), tenemos RL 27, Aurelius lulius, miles, sin especificar el cuerpo, cuya presencia puede asociarse a las actividades militares de apoyo a la producción minera y su transporte, cfr. $\mathrm{R}$. Lázaro Pérez, Inscripciones romanas de Almería, Almería, 1980, 16-17, recoge Abla como la primera mansio en la ruta Castulo-Malaca. 
por excelencia ${ }^{65}$, y en las regiones de explotación minera del noroeste peninsular ${ }^{66}$.

Ahora bien, aunque se atestigua la presencia de élites socioeconómicas en la familia, especialmente en la Bética, el acceso de éstas a los puestos dirigentes de la administración municipal se constata sólo excepcionalmente. Podemos sospechar la pertenencia a familias de notables municipales de $C$. Aurelius Crito en Malaca, donde financia en época flavia unas obras de restauración del teatro ${ }^{67}$, y de $L$. Aurelius Capratinus en el municipio bético de Aratispi a mediados del siglo II, como participante en la erección de una estatua a un ciudadano insigne del mismo ${ }^{68}$, pero sólo en Lusitania un miembro de la gens Aurelia ocupa explicitamente una magistratura municipal: M. Aurelius C.f. ${ }^{69}$, Ilvir y flamen Tiberii Caesaris Augusti en Pax Julia a comienzos del siglo । d.C. Igualmente, estos testimonios de

65 Testimonios en Tarraco de miembros de la legio VII Gemina: G. ALföLDY, Die romischen..., 38, T. Aurelius Decimus, centurio, praepositus, campidoctor, fin siglo ॥ d.C.; 188, Aurelius Severus, veteranus ex beneficiario consularis, fin siglo $॥ ; 178, M$. Aurelius Lucilius, de origen panonio, en su dilatada carrera militar fue centurio de la VII Gemina, lo que explica su presencia en Tarraco adscrito al servicio del gobernador, a fin del siglo $\|$ o principios del siglo III d.C.; 140, L. Aurelius Phileterus y $C$. Aurelius Octavius, speculatores, a comienzos del siglo Ill d.C. También en Tarraco, aunque no en la legio VII Gemina: AE 1977, 467, donde $M$. Aurelius lustus, centurio de procedencia oriental y dilatada carrera militar, debió desplazarse por asuntos administrativos, a comienzos del siglo III d.C.; También G. Alföldy, Die romischen..., 184, $M$. Aurelius Victorinus, militar de origen panonio, evocatus a finales del siglo II o comienzos del siglo III d.C.

66 Miembros de la legio VII Gemina: U. Espinosa, Epigratia de la Rioja..., 41, Aurelius Capito, miles, en San Millán de la Cogolla (Logroño), en la segunda mitad del siglo ॥ d.C.; AE 1928, 168, Aurelius lulianus, miles, en León, segunda mitad del siglo ॥ d.C.; D. Santos, Inscripciones de la provincia de León..., 144, Aurelius Fronto, centurio, también en León, de finales del siglo "l o inicio m; AE 1928, 173, M. Aurelius Victor, optio, igualmente en León, siglo III d.C., y 219. Aurelius Paternus Caesarianus, en Cacabelos (León), siglo ıll d.C., sugiere que es un miles de la legio VII Gemina; $F$. ARIAS/P. LE Roux/A. Tranoy, Inscriptions romaines de la province de Lugo, Paris, 1979, 24, L Aurelius [--], veteranus, en Lugo, siglo II d.C.

67 AE 1965, 56. P. Rooriguez OLIva, "Nuevas investigaciones sobre el teatro romano de Málaga", $T R H, 1993,188-189$, identifica esta inscripción con el momento de remodelación de la orchestra y parte de la decoración monumental de la scaena; $O$. Rodríguez Gutiérrez, "La función ideológica de los teatros romanos a través de su epigrafía", HAnt, XXIII, 1999, 199, incide en el atractivo del teatro romano para los ricos propietarios que asumían los cargos municipales, para quienes suponeía un espacio arquitectónico sobre el que actuar (construir, reconstruir, arreglar), aprovechando con frecuencia para dejar patente su fidelidad al emperador y a las estructuras oficales.

68 CIL II $2056=\mathrm{CIL}$ (2).5, 733. El monumento está dedicado a M. Fulvius Senecio, aratispitanus, optimus et praestantissimus cives ob merita, por miembros de una serie de familias que posiblemente formaban parte del ordo municipal: Licinii (4 dedicantes), Fabii (3 dedicantes), lunii (3 dedicantes). Flavii (2 dedicantes), Calpurnii (2 dedicantes), y con un dedicante Aemilii, Annii y Aurelii.

69 De 236, desempeñó también el puesto de praefectus fabrum, preparatorio para acceder a la carrera equestre; se trata de un pedestal de estatua erigido por decreto de los decuriones, $y$, aunque la autenticidad del documento suscita dudas, no se ha podido concluir de forma absoluta su falsedad. 
Crito, Capratinus y el lusitano $M$. Aurelius representan toda la implicación de miembros de la gens en fenómenos evergéticos y de honores públicos, estrechamente ligados a la forma de vida de las aristocracias municipales. En todo caso, la promoción de estos individuos y sus familias es considerablemente temprana, del siglo । y primera mitad del II d.C., lo que desvincula ésta de una posible influencia de los emperadores especialmente asociados al nomen Aurelius, es decir, Marco Aurelio o Caracalla.

El análisis de los lazos familiares de los Aurelii béticos y lusitanos, en aquellos casos en que la documentación epigráfica lo permite, descubre sus relaciones con una serie variada de grupos gentilicios, sin marcada predilección por alguno de ellos. En Bética los enlaces más tempranos constatados son con los Calpurnii en Teba (Málaga) ${ }^{70}$ en el siglo $\|$ d.C., entre individuos de estatus socioeconómico privilegiado, y ya en las últimas décadas del siglo $\|$ y siglo III d.C. conocemos enlaces con los Marii en Ilipa ${ }^{71}$, y los Flavii en el territorio de Salpensa ${ }^{72}$, aunque posiblemente éstos se producen a un nivel inferior, entre individuos de origen servil. En Lusitania a finales del siglo 10 principios del siglo $\|$ encontramos a los Aurelii unidos a los Gallii en Conimbriga ${ }^{73}$, enlace que afecta a individuos de un medio indígena romanizado. En el siglo II, también en Conimbriga, nuestro grupo gentilicio muestra lazos con los Aemilii ${ }^{74}$, a un

70 CIL $\| 1426=$ CIL $\|(2) .5,855$, Aurelia Fesenia-sic, patrona de cuatro libertos y Calpurnius Hartus. Los Calpurnii se encuentran bien atestiguados en toda Hispania, incluida la Bética, cfr. J.M. Abascal Palazón, Los nombres personales en las inscripciones latinas de Hispania, Murcia, 1994, 104-106. En la provincia de Málaga aparecen, además de en Teba, en Anticaria (CIL II 2049, 2050; HEp2, 461), Aratispi en la aristocracia local (CIL II 2056), Sabora (CIL II 1427, liberta?), Malaca (AE 1981,510), y en Nescania integrados en la aristocracia local (CIL II 2008, CIL. II 2042 y R. Atencia, “De epigrafía nescaniense», Baetica, 5, 1982, 116).

AAÑ 311, M. Aurelius (-) y Maria Q.f. Nymphe. La gens Maria está bien atestiguada en la Bética entre magistrados y élites socioeconómicas (cfr. J. GonzAlez FERnANDEZ, Corpus de inscripciones latinas de Andalucia, vol.Il.1, Sevilla, 1991, 82). En este caso Nymphe podria descender de libertos de este grupo gentilicio, e, iguaimente, ya hemos señalado la posible relación de Nymphe con conocidos diffusores olearii béticos. Sobre los Marii en Hispania, cfr. J.M. Abascal Palazón, Los nombres..., 182-183.

72 CIL II 1291, G. Aurelius Ampliatus y Flavia Prima. Sobre los Flavii, ampliamente constatados en Hispania, cfr. J.M. Abascal Palazón, Los nombres..., 138-141. En Lusitania teriemos a una Aurelia Flavia (CIL II 5323), esquema onomástico que podria responder también a algún enlace previo entre los Aurelii y los Flavii, aunque la falta de información sobre el entorno familiar de esta mujer no nos permite comprobar este extremo.

73 RE 45, donde Aurelia Gallif. Avita Restituta es probablemente la hija natural de M. Gallius Avitus, y se apunta a la posible raiz celta del cognomen Avitus/a. Gallius es un gentilicio poco frecuente en Hispania, constatándose puntualmente en Conimbriga otro caso(CIL II 376, una liberta). Cfr. J.M. Abascal. Palazon, Los nombres..., 145, recoge también Gallio como cognomen.

74 RE 46, Aurelius Vernaclus y Aemilia Fortunata. La gens Aemilia es el cuarto grupo gentilicio más numeroso en Hispania, estando también ampliamente constatado en Lusitania, cfr. J.M. ABASCAL PALAZÓN, Los nombres..., 29, 67-72. 
nivel secundario, entre libertos, y ya a finales del siglo II y siglo III d.C. con los Lucii en Caesarobriga ${ }^{75}$, los Atilii en Emerita ${ }^{76}$, los Laberii en Ebora ${ }^{77}$ y los Publii en Conimbriga ${ }^{78}$, éstos dos últimos casos también entre indigenas romanizados. Por otro lado, también se constatan algunos enlaces de tipo endogámico que expresan bien el origen servil de ambos cónyuges, o bien el acceso a la ciudadanía romana por parte de ambos en un mismo período ${ }^{79}$.

Finalmente, en relación a la esfera religiosa y votiva, la participación de la gens Aurelia se reparte entre cultos y divinidades romanos, orientales e indígenas en un pequeño grupo de testimonios puntuales. Los cultos romanos a los que se adscribe la familia manifiestan un evidente carácter estatal, el de luppiter Optimus Maximus, protector del Estado, en Ebora (Lusitania), y quizá lanus Augustus en lliturgi (Bética), en una dedicación tardía estrechamente relacionada con el ámbito oficial ${ }^{80}$. En cuanto a los cultos orientales, los Aurelii béticos y lusitanos manifiestan un comportamiento similar, ya que,

75 CIL II 5323, Aurelia Flavia y Lucius Murena. Los Lucii son poco frecuentes en Hispania, aunque en Lusitania contamos con algunos casos, especialmente en ambientes indigenas romanizados, cfr. J.M. ABASCAL PALAZÓN, LOS nombres..., 174-175.

76 CIL II 536, Aurelius Dorus y Atilia Nicopolis, aunque podrian ser individuos de procedencia oriental, quizá miembros de alguna comunidad de comerciantes extranjeros. Por lo demás los Atilii están bien constatados en Hispania, cfr. J.M. ABASCAL. PALAZÓN, Los nombres..., 86-87.

77 De 426, donde $G$. Aurelius Victorinus dedica el monumento a su matertera (tia materna) a Laberia Nigra, lo que indica que es hijo de un Aurelius y una Laberia. Las evidencias epigráficas de este tipo de parentesco por línea femenina se han venido asociando a la tímida pervivencia de antiguas estructuras socioeconómicas prerromanas, cfr. H. Gallego Franco, Femina Dignissima. Mujer y sociedad en Hispania Antigua, Valladolid, 1991, 41. Por otro lado, la aparición de un $M$. Aurelius Laberianus en Conimbriga (RE 44) también puede apuntar a la existencia de enlaces entre ambos grupos gentilicios. Los Laberii no son muy numerosos en Hispania, pero sí presentan un carácter notable en Lusitania, especialmente en torno a Ebora, donde conocemos a la flaminica provincial Laberia Galla (CIL II 114 y 339), cfr. J.M. ABASCAL PALAZÓN, Los nombres..., 167.

78 RE 44, M. Aurelius Laberianus y Publia Avita, donde se apunta a la posible raiz celta del cognomen Avita. Los Publii aparecen raramente en Hispania romana, y en Lusitania los escasos ejemplos aparecen sólo en Conimbriga (CIL II 382, Publia Procula), cfr. J.M. AbAsCAL PaLAZÓn, Los nombres..., 206.

79 CG 90, Aurelia Afrodisia y su contubernalis Aurelius Myrismus en Italica; RE 31, la igualdad de gentilicio entre Aurelia Prisca y su hijo L. Aurelius Rufus en Conimbriga puede obedecer a un origen servil de Prisca y su marido, que pudieron tener en mismo patrono. AE 1972, 237, en Emerita, donde Aurelius Donatus debe ser el segundo esposo de Aurelia Sotira, unida previamente a un Septimius. Ambos esposos pudieron recibir la ciudadanía romana bajo el reinado de Caracalla, lo que explicaría la igualdad de nomina entre ambos. Cfr. J.F. RodRiguez NEILA/F. ChAVES TRISTAN, "Un monumento funerario procedente de Emerita", Habis, 4, 1973, 295-310.

${ }^{80}$ DE 373, Aurelius [-], en un epígrafe deteriorado que puede fecharse en los ss. II-III, y en el que no conocemos más datos del dedicante. CIL II(2).7, 33, Aurelius Marcellinus y otros milites praetoriani dedican, en la primera mitad del siglo III d.C., a una divinidad cuyo nombre se ha perdido, pero que podría ser lanus Augustus, dios itálico que simboliza el paso de una cosa a otra, por el lugar de erección del monumento, en la "puerta" de la Bética (cerca del límite con la Tarraconense); el voto debe estar en relación con las actividades del aprovisionamiento de la annona. 
aunque de forma minoritaria, los únicos que encuentran eco en la familia, ya en el siglo III d.C., son los de Nemesis ${ }^{81}$ y la Mater Deum, es decir, Cybeles ${ }^{82}$, a cuyo servicio conocemos al sacerdos Aurelius Stephanus en Corduba ${ }^{83}$. Los documentos aparecen en importantes núcleos urbanos de estatus privilegiado, muy romanizados, como son Emerita, Corduba e Italica, a menudo con una fuerte actividad comercial y trasiego cultural, y los miembros de la gens Aurelia implicados en los mismos parecen ser extranjeros en nuestras provincias $^{84}$.

También reviste un carácter puntual la participación de este grupo gentilicio en cultos de raíz indígena prerromana. Sin embargo, resulta interesante que en los dos casos constatados élites socioeconómicas se relacionen con este tipo de divinidades. Asi, en Lusitania, la dama Aurelia Vibia Sabina podría ser simpatizante del culto al Deus Endovellicus, al aparecer cuidadosamente explicitada como dueña de un esclavo que erige un ara a esta divinidad en su santuario de S. Miguel da Mota (Terena, Portugal), en la segunda mitad del siglo ॥ d.C. En la Bética, Aurelius

81 AE 1984, 503, Aurelius Polyticus dedica a Nemesis Praesens en Italica a comienzos del siglo ili d.C.; AE 1961, 48, M. Aurelius Fili[- -], natural de Roma, dedica a la Dea Invicta Caelestis Nemesis, a finales del siglo II o comienzos del siglo III d.C., en Emerita. Este último monumento ha sido objeto de una doble interpretación, bien como una asociación de Némesis a la Dea Caelestis de origen púnico, viendo en caelestis simplemente un epíteto de la diosa, cfr. F. FORTEA LOPEZ, Némesis en el Occidente Romano. Ensayo de interpretación histórica y corpus de materiales, Zaragoza, 1994, n. 71.

${ }_{82}$ Sobre los origenes frigios de Cybeles y su expansión en el Mediterráneo oriental, cfr. F. Graf, "The arrival of Cybele in the Greek East", Actas du VII Congrès de la Fédération Internationale des Associations d'Etudes Classiques, Budapest, 1984, 117-120. Sobre la introducción del culto a Cybeles en Roma, sus vicisitudes y proceso de adaptación, cfr entre otros, M.J. Vermaseren, Cybele and Attis. The Myth and the Cult, Londres, 1977, 38 ss. y 96-99; J. Bremmer, "The Legend of Cybele's arrival in Rome", Studies in Hellenistic Religions, 1979, 9-23; G. THOMAS, "Magna Mater and Attis", ANRW, 17.3, 1984, 1502-1512; G. SFAMENI GASPARRO, Soretiology and mystic aspects in the Cult of Cybele and Attis, Leiden, 1985, 56-63; F. Cumont, Las religiones orientales y el paganismo romano, Madrid, 1987, 55; R. TURCAN, Les cultes orientaux dans le monde romain, París, 1989, 36-57; I. BECHER, "Der Kult der Mater Magna in augusteischer Zeit", Klio, 73/1, 1991, 157-170.

83 CIL II 5521, donde en el epígrafe que conmemora el tauribolium celebrado por Valerius Fortunatus Thalamas en Corduba en el 238 d.C. figura Aurelius Stephanus como sacerdos Matris Deum. Sobre el sentido del término tauribolium en el culto de la diosa frigia, cfr. R. DuthoY, The Taurobolium. Its Evolution and Terminology, Leiden, 1969, 72 ss.. Aunque en Lusitania aparecen representaciones de la imagen de Attis y/o Cybeles en relieve sobre objetos diversos (lámparas, jarras...), o estatuillas y fragmentos de estatuas, y es posible que algunos de estos objetos hayan estado relacionados con el culto de Magna Mater, parece improbable que cada uno de ellos responda a una vinculación personal del propietario o de su entorno de hallazgo con la divinidad mistérica, cfr. J. ALVAR, "Los cultos mistéricos en Lusitania», // Congreso Peninsular de Historia Antigua, Coimbra, 1993, 798.

${ }_{34}$ Tanto $M$. Aurelius Fili - - ] en Emerita, procedente de Roma, como el sacerdos Aurelius Stephanus en Corduba y Aurelius Polyticus en Italica muestran cognomina griegos que bien podrían apuntar a un origen oriental de sus portadores. 
Manus, un adinerado comerciante de Arva, cumple un voto a Arescus, quizá una divinidad de las aguas, en el siglo III d.C. ${ }^{85}$.

La implicación de la gens Aurelia en el culto imperial resulta especialmente temprana en Lusitania, donde encontramos un flamen Tiberii Caesaris Augusti en Pax lulia ya en las primeras décadas del siglo I d.C., mientras en la Bética el testimonio más temprano se ubica en el siglo $\|$ d.C., una consagración votiva a los Augusti Lares ${ }^{86}$. Sin embargo, los monumentos en honor de los emperadores de turno revisten en todos los casos, tanto béticos como lusitanos, un carácter muy tardío, de mediados del siglo III d.C. en adelante, y emanan, como es propio de la época, no ya del ámbito urbano y las élites municipales sino de la esfera oficial y los cargos de la administración imperial provincial ${ }^{87}$. Finalmente, también en este período bajoimperial y de Antigüedad Tardia, hay que mencionar la presencia de Aurelii en comunidades cristianas primitivas de Emerita, Gades, Corduba y Malaca, entre cuyos miembros encontramos algún comerciante norteafricano e individuos de cierto nivel social ${ }^{88}$.

En conclusión, a través de las fuentes epigráficas, desde el punto de vista onomástico la gens Aurelia constituye en la Hispania Ulterior un grupo altamente romanizado, en el que las pervivencias indígenas se constatan con poca frecuencia, bien en forma de algún esquema de nombre único o de algunos cognomina de raíz prerromana. El notable predominio de los esquemas de duo nomina en los varones es acorde con el hecho de que la mayor parte de la documentación epigráfica de la gens se situe en la segunda mitad del siglo $\mid$ y primera mitad del siglo III d.C. El

85 De 497, el dedicante es Hermes, servus marmorarius. A. HoLdER, Alt-Celtischer...l, 14361437; AAÑ 222; P. PIERnAVIEJA, “Denudator gimnasi...", 359-379, possessor leopardorum, dedicado a la importación de animales salvajes para los espectáculos de las ciudades béticas, y deportista aficionado (denudator gimnasi); el exvoto es una barca de terra sigillata, ofrendada quizá porque los leopardos se salvaron de algún accidente de transporte, por lo que Arescus podria ser un dios protector de los viajes realizados por agua.

86 De 236, M. Aurelius C.f. Gal., tambièn Ilvir y praefectus fabrum. EE IX, 151, T. Aurelius Faustus en Jerez de los Caballeros (Badajoz), cerca de Nertobriga.

87 En la Bética: CIL II(2).7, 259, M. Aurelius Alexander, procurator Augustorum y agens vices praesidis, quizá a Valeriano o Galieno a mediados del siglo $\|$ en Corduba; CG 36, Aurelius Ursinus, curator reipublicae Italicensium, y Aurelius lulius, agens vicens praesidis et curator rejpublicae Italicensium, a Floriano, junto con la respublica Italicensium; CG 37, el mismo Aurelius Iulius a Probo, también junto con la respublica Italicensium. Parece que en el momento de ambas dedicatorias la Bética era una provincia imperial al mando de un praeses a causa de las invasiones de los Mauri. En Lusitania, DE 5, Aurelius Ursinus, praeses provinciae, probablemente a Diocleciano en Ossonoba.

88 MGI 40, Aurelia Licinia Florida en Emerita. CCG, p.455, Aurelius Felix Ingenuus, carteiensis, en Gades; AV p.155, Aurelius Felix?, y CIL II 5528, Aurelius/a en Corduba; MG p.248, Aurelius Iulianus en Malaca, aunque se trata de un individuo de origen norteafricano, seguramente un comerciante. 
hecho de que el praenomen $M$ (arcus) sea el más representado en la familia se explica por similares razones cronológicas. En consecuencia, los tria nomina afectan sólo a una tercera parte de los varones de la familia, siendo sus portadores individuos de condición social variada, aunque con cierta frecuencia manifiestan un nivel socioeconómico destacado. Otro elemento onomástico, la tribu, se constata poco, aunque siempre asociada a ciudadanos romanos de origen autóctono y buena situación social en un momento temprano de la época altoimperial. Por el contrario la mención de la origo se corresponde con una cronología ya tardía, a partir del siglo III d.C., y explicita un desplazamiento de su portador, si bien de distinto alcance ${ }^{89}, y$, aunque no siempre es posible averiguar sus causas, en buena medida por motivos profesionales. Pero además otros indicadores onomásticos, en especial la presencia de cognomina griegos, pueden apuntar a una procedencia foránea de los portadores, en concreto oriental: encontramos en esta situación una posible pareja de comerciantes dálmatas en Emerita, individuos vinculados a cultos orientales, una familia de propietarios de figlinae postseveriana y algún miembro de la administración provincial bajoimperial.

Reflejo de esta alta romanización onomástica de la gens Aurelia es el hecho de que la mayor parte de los cognomina portados por sus integrantes sean latinos. Este protagonismo, sin embargo, es más brillante en Lusitania que en la Bética, provincia ésta última que ofrece la peculiaridad de registrar una notable incidencia de los cognomina griegos entre los Aurelii. Los portadores de estos antropónimos griegos suelen ser varones ubicados en medios urbanos, presumiblemente procedentes en su mayoría del ámbito de las relaciones de dependencia personal. Ahora bien, en general el origen servil se explicita sólo puntualmente entre los Aurelii béticos y lusitanos, lo que puede constituir simplemente un indicativo de las buenas posibilidades de promoción social que los libertos de cierto nivel económico y sus descendientes tenían a su alcance en Lusitania y sobre todo en la Bética, especialmente aquellos insertos en ámbitos urbanos muy romanizados, y que la evidencia de una ascendencia dependiente podría perjudicar. Finalmente, el estudio de los cognomina derivados Aurelianus/a, así como de la aparición del nomen Aurelius como segundo gentilicio en esquemas onomásticos refuerza la incidencia de la gens Aurelia en la Bética, especialmente entre las élites urbanas.

89 De nivel extraprovincial hemos constatado un desplazamiento desde Roma a Emerita, otro desde Cibalis en Pannonia al territorio de Obulco y otro desde Africa a Malaca. Ya a un alcance intraprovincial tenemos un desplazamiento de Astigi a Iponoba, otro de Carteia a Gades y otro de Conimbriga a Emerita. 
En cuanto a los aspectos sociales, la presencia de miembros del ordo senatorial en la gens Aurelia es puntual y muy tardía, ya en el siglo $\vee$ d.C. Algo más numeroso es el grupo equestre, integrado por altos cargos de la administración provincial bajoimperial, individuos de procedencia foránea exponentes del creciente protagonismo de los cuadros de caballeros en la administración de ese momento, y responsables del comportamiento evergético y del culto imperial de nuestro grupo gentilicio en esta etapa tardía. Las aristocracias municipales se constatan sólo de forma excepcional en las ciudades béticas de Malaca, en época flavia, y Aratispi a mediados del siglo ॥ d.C., y en la lusitana de Pax lulia a comienzos del siglo I d.C., en documentos epigráficos relacionados con los fenómenos evergéticos y de honores públicos estrechamente ligados con la forma de vida de las élites urbanas altoimperiales. A pesar de ello, algunos miebros de los Aurelii alcanzaron una notable promoción económica en el siglo $\|$ y primeras décadas del siglo III d.C. Una evidencia de ello es su posición de dueños de esclavos y patronos de libertos en Teba del Condado (Málaga), Italica, Pax lulia, Conimbriga y la zona de Vila Viçosa. Ahora bien, los antropónimos griegos constatados en la familia nos hacen sospechar que sus redes de dependencia privada se extendian también a otros núcleos urbanos de Lusitania (Aeminium, Emerita, Myrtilis) y sobre todo Bética (Sabora, Tucci, Iponoba, Corduba, Hispalis, Ilipa). En cambio, la presencia de élites de libertos imperiales significativa entre los Aurelii de la Tarraconense, es muy reducida en la Ulterior, constatándose tan solo un tabularius rationis patrimonii provinciae y su hermano en Emerita, la capital y centro administrativo de Lusitania.

El análisis de las fuentes epigráficas recogidas permite la identificación de algunas de las fuentes de riqueza de la gens, o al menos de algunos de sus miembros. Es el caso de las actividades comerciales, que propician la presencia de Aurelii procedentes de la parte oriental del Imperio en Emerita Augusta en época Severa y de norteafricanos en Malaca en época bajoimperial. La importación de animales salvajes para los espectáculos béticos es la fuente de la fortuna de Aurelius Manus en Arva en el siglo III d.C. Además, para la gens Aurelia de la Bética la producción y comercialización del aceite de oliva constituye otra importante fuente de ingresos a lo largo del siglo II y primeras décadas del siglo III d.C. En este sector económico intervienen miembros de la familia como propietarios de figlinae, dueños de fundi y como mercatores o diffussores olearii. También hemos constatado la implicación de algún integrante de la gens Aurelia en la explotación de canteras en Lusitania. En cambio, el servicio en el ejército como actividad profesional presenta una incidencia meramente testimonial entre los Aurelii béticos y lusitanos, ya que ambas son en esencia 
provincias desmilitarizadas, de manera que los pocos casos constatados se ponen en relación sobre todo con apoyos puntuales a actividades de explotación económica y a las redes de comunicación en estas provincias.

Podemos calificar el comportamiento votivo de la gens Aurelia de Bética y Lusitania como tímido, y, sin embargo, las diferentes categorías principales del mundo religioso romano encuentan eco, aunque reducido, en la familia: cultos romanos, orientales, indígenas y cristianismo primitivo. luppiter Optimus Maximus y quizá lanus Augustus son las divinidades romanas constatadas, en dos documentos próximos a la ideología oficial. Por otro lado, el culto imperial presenta poca incidencia en el grupo gentilicio en época altoimperial, con la excepción de la presencia de un flamen de Tiberio en Pax lulia (Lusitania) y una votiva a los Lares Augusti en la Bética. En cambio las dedicaciones honoríficas que muestran la adhesión a emperadores reinantes aparecen en los Aurelii béticos y lusitanos tardíamente, a partir del mediados del siglo III d.C., vinculadas a los integrantes de la esfera gubernamental oficial. Los cultos greco-orientales de Nemesis, Nemesis/Dea Caelestis y Mater Deum penetran en nuestro grupo gentilicio ya en el siglo III d.C., pero dudamos hasta qué punto tuvieron una auténtica acogida entre los Aurelii, ya que los individuos implicados en los mismos, ubicados en núcleos urbanos muy romanizados de notable dinamismo económico y cultural (Emerita, Corduba, Italica), parecen de origen extraprovincial. En cuanto a los cultos indígenas, el de Endovellicus en Lusitania, donde el dios gozó de notable popularidad, y el de Arescus en Bética, el rasgo más interesante es que ambos se relacionan con Aurelii miembros de élites autóctonas de importante nivel socioeconómico. Finalmente, también encontramos el gentilicio Aurelius en miembros de las primitivas comunidades cristianas de Emerita Augusta en Lusitania, y Gades, Corduba y Malaca en Bética.

En definitiva, la gens Aurelia en Bética y Lusitania aparece integrada por un grupo selecto de altos cargos de la administración central bajoimperial, ajenos a la provincia (praesides, procuratores, agentes vice praesidis, curatores reipublicae) en torno a los cuales gira una parte significativa de los fenómenos de evergetismo y culto imperial; unas escasisimas élites municipales que ocupan algún cargo público (//vir, decurio, flamen) y de los que emaman las restantes actuaciones en relación al evergetismo y los honores públicos; un grupo de individuos muy activos en el aspecto socioeconómico, sobre todo en Bética, implicados en las redes de dependencia personal como dueños y patronos, en las actividades comerciales y en la explotación de recursos naturales como las canteras y sobre todo el aceite de oliva; un núcleo meramente testimonial de militares relacionados con actividades de abastecimiento y vias de comunicación provinciales; 
un sector de cierta entidad, en su mayor parte encubierto, de libertos privados o sus descendientes en ambientes urbanos (Teba, Italica, Sabora, Tucci, Iponoba, Corduba, Hispalis, llipa en Bética y Pax lulia, Conimbriga, Aeminium Emerita, Myrtilis y Vila Viçosa en Lusitania); finalmente, una masa de individuos modestos pero de onomástica muy romanizada, seguramente en su mayoría ciudadanos romanos, de los que apenas sabemos algo más que el nombre y que suponen cerca de la mitad de los componentes de la gens en ambas provincias.

La gens Aurelia se constata en los cuatro conventos jurídicos béticos, si bien de forma desigual. Muestra una expansión preferente en el convento hispalense, todavía notable en el astigitano y cordubense y ya sólo contamos con testimonios puntuales en el gaditano ${ }^{90}$. Los miembros del grupo gentilicio se atestiguan epigráficamente en un número notable y variado de municipios y colonias de estas zonas, pero las concentraciones más importantes se localizan en Corduba, Italica y Teba del Condado (Málaga), en los conventos cordubense, hispalense y astigitano respectivamente, de manera que entre las tres ciudades reunen más de una tercera parte $(43 \%)$ del total de testimonios provinciales. Desde el punto de vista cronológico, a nivel global la mitad de los Aurelii béticos se ubican en las últimas décadas del siglo $\|$ y siglo III d.C. Sin embargo el gentilicio aparece ya en las fuentes epigráficas provinciales en el siglo | y comienzos del siglo $\|$ d.C. $(10 \%$ de los testimonios), período en el que lo encontramos ya en los cuatro conventos béticos ${ }^{91}$, consolidándose a lo largo del siglo $\|(20 \%$ de los testimonios), con especial protagonismo en el convento astigitano ${ }^{92}$, para llegar

90 El convento hispalense reune el $41 \%$ de los testimonios de la gens Aurelia en Bética. Italica aporta el conjunto más numeroso, en menor medida Hispalis y Arva, y ya más puntualmente tenemos documentos en Ilipa, Nabrissa, Salpensa y hacia el limite con la Lusitania en el territorio de Arucci, en Jerez de los Caballeros (Badajoz, cerca de Nertobriga) y la zona de Messangil (Serpa, Portugal). El convento astigitano aporta el $29 \%$ de los testimonios del grupo gentilicio: Teba del Condado (Málaga) reune en grupo mayor, a los que hay que añadir los testimonios de Astigi, Sabora, Tucci, Marchena (Sevilla), Aratispi, y Carmo. El convento cordubense aporta el $25 \%$ de testimonios de Aurelii béticos, con la peculiaridad de que éstos se concentran en Corduba, mientras los restantes núcleos aportan un solo testimonio en cada caso (Iponoba, Igabrum, Sacili, Iliturgi, Obulco). El convento gaditano aporta un 5\% de los testimonios del grupo gentilicio, localizados en dos ciudades, Gades y Malaca.

91 El testimonio más temprano procede de Jerez de los Caballeros (Badajoz), cerca de Nertobriga y próximo al límite con la Lusitania, un miles de la legio $X$ Gemina a comienzos del siglo I d.C.; otros en Sabora, Arucci, Sacili, Malaca y Tucci.

92 Los testimonios de este período proceden sobre todo del convento astigitano: Teba del Condado (Málaga), Astigi, Marchena (Sevilla), Aratispi. Puntuaimente también en las capitales del cordubense e hispalense, es decir, Corduba e Hispalis, y en este ültimo también en la zona de contacto con la provincia Lusitania, en Jerez de los Caballeros (Badajoz) y Messangił (Serpa, Portugal). En definitiva, en el período altoimperial la huella epigráfica de la gens Aurelia aparece primero en el convento hispalense, en la zona de contacto con Lusitania, es decir, en Jerez de los 
a su momento de máxima presencia desde finales de esa centuria y durante la siguiente, cuando toman auge los conjuntos de los conventos hispalense y en menor medida cordubense ${ }^{93}$. La familia muestra además una notable pervivencia en época bajoimperial y en la Antigüedad Tardía, entre los sigos IV-VI d.C. (13\% de los testimonios), especialmente en los conventos cordubense y gaditano ${ }^{94}$.

En Lusitania la gens Aurelia se constata también en los tres conventos jurídicos provinciales de forma bastante equilibrada, aunque con mayor protagonismo del convento emeritense ${ }^{95}$. Al igual que en la Bética, su distribución es eminentemente urbana, y más concentrada en torno a determinados núcleos concretos, ya que casi las dos terceras partes de los integrantes del grupo gentilicio se ubican en Emerita Augusta, la capital provincial, y Conimbriga sobre todo, y ya en menor medida Caesarobriga,

Caballeros y el territorio de Arucci, así como en Sacili (convento cordubense), Malaca (convento gaditano) y Sabora (convento astigitano). Ya entrado en siglo $\|$ d.C. el gentilicio se multiplica en el convento astigitano (testimonios de Teba, Marchena, Tucci, Aratispi, Astigi), aparecen también testimonios en el hispalense (de nuevo la zona limítrofe con Lusitania, es decir, Jerez de los Caballeros y Messangil, y en Hispalis), y en el cordubense, ahora en Corduba.

93 Ahora, en cambio, cobra auge el grupo del convento hispalense, donde destaca en especial el núcleo de Italica, que se centra sobre todo en el siglo III d.C., y constatamos testimonios también en los de Hispalis, llipa, Salpensa, Nabrissa, y Arva; continúa también la presencia de la gens en Corduba, que se amplia a otros puntos del convento cordubense, como lponoba, Iliturgi y Obulco. El convento astigitano aparece representado sólo por algunos testimonios de Teba (Málaga).

94 En este momento tardio el gentilicio se constata sobre todo en el convento cordubense, en Corduba e Igabrum, en el gaditano, en Malaca y Gades, y en menor grado en el hispalense, en Hispalis, y astigitano, en Tucci. En conclusión, a partir del siglo III d.C. los Aurelii béticos se localizan especialmente en el convento hispalense, donde sobresale el grupo de italica, que se centra por completo en esta centuria, continúa atestiguándose el gentilicio en Hispalis, y aparece por vez primera en Ilipa, Salpensa, Nabrissa y Arva, así como en el convento cordubense, donde se consolida enormemente la presencia de la familia en Corduba, ciudad en la que casi la totalidad de los documentos se ubican a partir de finales del siglo $॥$, además de constatarse en nuevos enclaves (Iponoba, Igabrum, lliturgi y el territorio de Obulco). En cuanto al convento astigitano, en el que la familia tiene gran difusión en el siglo 11 , a partir del ॥I d.C. hay un notable descenso de los testimonios, aunque el gentilicio continúa presente en Teba, Tucci (muy tardiamente), quizá Astigi, y pudo aparecer en Carmo. El convento gaditano aporta dos testimonios muy tardios, del siglo IV en adelante, en Gades y Malaca. Resultan peculiares los casos de Malaca y Tucci, donde la gens Aurelia tiene una presencia temprana, de finales del siglo 10 comienzos del siglo il, no encontrándose nuevos testimonios hasta un momento muy tardio (IV-VI d.C.).

95 El $40 \%$ de los testimonios epigráficos de Aurelii lusitanos proceden del convento emeritense, donde la aportación mayor la realiza Emerita Augusta, seguida ya a distancia por Caesarobriga, y finalmente con testimonios puntuales en Norba, Avela e Hinojosa de Duero (Salamanca). Sigue en importancia la aportación del convento scalabitano (35\%), donde el mayor conjunto se reune claramente en Conimbriga, aunque contamos también con testimonios en Aeminium, Olisipo, y al norte, cerca del Duero, en el área de Viseu (Cárquere y Beijós). Finalmente, el convento pacense, la parte sur provincial, aporta la cuarta parte restante de los testimonios recogidos, con un protagonismo similar de los núcleos de Pax lulia, Ebora y el entorno de Vila Viçosa, y testimonios puntuales en Myrtilis y Ossonoba. 
la zona de Vila Viçosa y Pax lulia. En relación a su distribución cronológica, el gentilicio Aurelius se constata en los tres conventos lusitanos tempranamente, incluso en mayor grado que en Bética, ya que en el siglo । y principios del siglo $\|$ d.C. ubicamos un $20 \%$ de la huella epigráfica de la familia ${ }^{96}$. Su presencia continúa a lo largo del siglo $\|(15 \%){ }^{97}$, pero, al igual que en Bética, es desde finales de esta centuria y durante la siguiente, siglo III d.C., cuando localizamos el mayor número de testimonios del gentilicio en la provincia (48\%) ${ }^{98}$, en la que también perdura puntualmente $(5 \%)$ en la época bajoimperial y la Antigüedad tardía (ss. IV-VI d.C.) en Emerita y Olisipo ${ }^{99}$.

En conclusión, aunque debemos tener en cuenta la ausencia de una datación realmente precisa en buena parte de la documentación aportada, el análisis detallado de ésta evidencia claramente que la consolidación del gentilicio Aurelius en la Bética y Lusitania se produjo en el siglo ॥ d.C., con anterioridad a la Constitutio Antoniniana del 212 d.C. Dejando a un lado los altos cargos de la administración estatal, los libertos imperiales y los extranjeros en ambas provincias, un grupo sustancial de los integrantes autóctonos de la gens, que oscila entre un $23 \%$ en Bética y un $34 \%$ en

96 De ser auténtico, punto éste que ha suscitado dudas, el testimonio más temprano de los Aurelii lusitanos procedería de Pax lulia, y se trata de un individuo de la aristocracia municipal, DE 236. M. Aurelius C.f. Gal. IVir, flamen Tiberii Caesaris Augusti y praefectus fabrum. Para este periodo del siglo I y principios del siglo $\|$ d.C. contamos algún otro documento en el convento pacense, también en la zona de Vila Viçosa, así como en el emeritense, en Emerita Augusta, y en el scalabitano, en Conimbriga, Olisipo, y Beijós (Carregal do Sal, Viseu), al norte del convento.

97 A lo largo de esta centuria continúa la presencia de la familia en la zona de Vila Viçosa (convento pacense), asi como en Conimbriga (convento scalabitano) y en el convento emeritense, no ya en Emerita sino en Caesarobriga y Norba. En definitiva, en la etapa altoimperial (ss. I- $\|$ d.C.) los Aurelii lusitanos se distribuyen en Emerita, Caesarobriga y Norba en el convento emeritense, en Pax Iulia y la zona de Vila Viçosa en el pacense y en Conimbriga, Olisipo y Beijós (Carregal do Sal, Viseu) en el scalabitano. En algunos de estos puntos la huella epigráficas del gentilicio no continúa tras este período, en concreto en la zona de Vila Viçosa, Norba, y Beijós

98 En este período los conjuntos más significativos los aportan los núcleos de Emerita Augusta y Conimbriga, al mismo tiempo que recogemos testimonios puntuales en otro puntos de los conventos emeritense (Avela, Hinojosa de Duero en Salamanca) y scalabitano (Aeminium. Cárquere en Viseu), en los que se atestigua ya la presencia de ámbitos de menor romanización, asi como en el convento pacense (Ebora, Myrtilis, Ossonoba).

99 En conclusión, desde el siglo III d.C. en adelante, y tomando como referencia el anterior período altoimperial, los Aurelii lusitanos se atestiguan sólidamente en Emerita y Conimbriga, ciudades en las que la mayor parte de los testimonios de la familia se localizan a partir de finales del siglo II d.C. Además, encontramos por primera vez el gentilicio en varios puntos del norte de la provincia, algunos de ellos de romanización deficiente (Avela, Aeminium, Hinojosa, Cárquere) y en varias ciudades del sur, en el convento pacense (Ebora, Myrtilis, Ossonoba). Es posible que dos núcleos en los que la gens se atestiguaba en época altoimperial, Caesarobriga y Pax Iulia, mantuvieran miembros de la misma en un período posterior. Finalmente, señalar la peculiaridad de Olisipo, donde la gens Aurelia presenta testimonios en momentos cronológicos extremos, a finales del siglo I o comienzos del siglo $\|$ d.C., y ya a comienzos del siglo Iv d.C. 
Lusitania, parece disfrutar de derechos de ciudadanía (romana o latina) ya desde el siglo I y durante el siglo || d.C. ${ }^{100}$, integrándose algunos de sus miembros en las élites socioeconómicas y municipales en este período ${ }^{101}$.

Esta evidente y sólida implantación del gentilicio Aurelius en la etapa altoimperial, desde sus inicios, y el dinamismo propio de los mecanismos de romanización progresiva en los núcleos urbanos privilegiados, en los que se ubica la práctica totalidad de la gens (tales como la latinidad, la expansión de las relaciones de dependencia y clientela...) pueden explicar suficientemente por sí solos la expansión cuantitativa de los Aurelii en las fuentes epigráficas en las últimas décadas del siglo II y la primera mitad del siglo III d.C., especialmente importante en Bética ${ }^{102}$, sin tener

100 En este primer siglo del Imperio la aparición epigráfica del gentilicio se debe hallar unida a la entrada y asentamiento, deste etapas ya anteriores, de elementos itálicos, civiles o militares. Poca fue la posible influencia de las élites senatoriales y equestres en la expansión del gentilicio Aurelius en las provincias hispanas de Bética y Lusitania: su huella epigráfica es muy tardia, bajoimperial, y para entonces al gentilicio estaba ya bien consolidado en ambas provincias. En Bética: AE 1980, 562, M. Aurelius M.f. Gal. Abbicus, miles legionis, en Jerez de los Caballeros (Badajoz), cerca de Nertobriga, a comienzos del siglo I d.C.; AE 1965, 56, C. Aurelius Gal. Crito, posible miembro de la élite local en Malaca en época flavia; CIL II(2).7, 207, L. Aurelius Lucanus, en el territorio de Sacili, a finales del siglo । d.C.; AE 1983, 525, Aurelia Euprosine-sic, quizá una liberta, en Sabora, y CIL II 969, Aurelia M.f. Galla, en el territorio de Arucci, ambas a finales del siglo 1 o comienzos del siglo II d.C. En Lusitania: DE 236, M. Aurelius C.f. Gal., miembro de la aristocracia municipal de Pax lulia a comienzos del siglo I d.C.; DE 445, L. Aurelius L.f. Flaus y su hermano P. Aurelius Niger en Bencatel (Vila Viçosa) en el siglo I d.C.; CIL II 571, Aurelia Quintilla en Emerita Augusta, en el sigio । d.C.; CIL II 203, M. Aurelius M.f. Gal. Marinus en Olisipo, quizá del siglo I o comienzos del siglo II d.C.; AE 1977, 378, Aurelius Hispanianus en Beijós (Viseu), y RE 45, Aurelia Galli f. Avita Restituta, miembro quizá de una familia de la élite indigena tempranamente romanizada en Conimbriga, ambos documentos de finales del siglo I o comienzos del siglo $\|$ d.C. Nótese en este pperíodo temprano la presencia ya de individuos de las élites y aristocracias locales.

101 En el siglo ॥ d.C., en Bética, conocemos EE IX,151, T. Aurelius Faustus en Jerez de los Caballeros (Badajoz); ILER 3333, Aurelia Arconis f. Annia, en un ambiente de pervivencias indígenas en Messangil (Serpa); CIL II 1393, Aurelia Capitolina en Marchena; CIL II 1426, Aurelia Fesenia-sic, patrona de cuatro libertos, los Aurelii Antullus, Cupitus, Germanus y Euhemerus, en Teba (Málaga); JJO 453, Aurelia Leucothoe, quizá una liberta, en Tucci; CIL II(2).5, 1177, Aurelius Carus en Astigi; CIL II 2056, L. Aurelius Capratinus, miembro de la aristocracia municipal de Aratispi; AAÑ 105, M. Aurelius L.f. [--J en Hispalis; CIL II(2).7, 423, Aurelia Marciana en Corduba. En Lusitania, también en el siglo II d.C., ILER 5668, Aurelia [--], relacionada con un veterano de la legio $X$ Gemina en Emerita; CIL II 5342, Aurelia Vitalis y su hermano Aurelius Cosconianus, y CIL II 5323, Aurelia Flavia, ambos documentos en Caesarobriga; ILER 3341, Aurelius Caecilius en Norba; RE 46, Aurelia Materna, patrona de Aurelius Vernaclus y quizá de su hijo Aurelius Rufus en Conimbriga; DE 497, Aurelia Vibia Sabina, dueña de un servus marmorarius en la zona de Vila Viçosa. Por tanto, también en esta centuria algunos miembros de la gens se integran en las élites socioeconómicas y municipales. Igualmente, en el siglo ॥l la epigrafía olearia revela la implicación de Aurelii como propietarios de fundi y como mercatores en el comercio de aceite bético, como ya hemos puesto de manifiesto.

102 Contamos con un buen número de testimonios que se ubicarian en este período cronológico, sin poder precisar con más exactitud el momento. Así, en Lusitania: RE 31, Aurelia Prisca y 
que recurrir a la actuación de medidas extraordinarias y exteriores a la dinámica social interna de estas provincias hispanas, como es el edicto de Caracalla.

Sólo en casos puntuales de la documentación epigráfica analizada parece suficientemente probable que miembros de los Aurelii béticos y lusitanos accedieran a la ciudadanía gracias al edicto de Caracalla ${ }^{103}, y$, de hecho, atendiendo a la evolución cronológica expuesta, juzgamos que debió ser significativa la influencia que en la popularidad de nomen y su adopción por los nuevos ciudadanos debieron tener en estas provincias los reinados de los últimos Antoninos, Marco Aurelio y Commodo, sobre todo el primero, ligado por lazos familiares a la Bética ${ }^{104}$. Sin duda el impacto de la Constitutio Antoniniana en las provincias hispanas fue reducido, como ciertamente es la opinión generalizada, si bien, a la luz de las fuentes epigráficas, éste resulta especialmente diluído en Bética y Lusitania, en comparación con la Tarraconense ${ }^{105}$. Aún así, es posible que cierto eco de la

su hijo $L$. Aurelius Rufus, RE 44, $M$. Aurelius Laberianus y su hijo $M$. Aurelius Avitus, todos ellos en Conimbriga; CIL $\| 368$, Aurelius Musaeus y su hijo Aurelius Rufinus en Aeminium; DE 426, G. Aurelius Victorinus en Ebora; CIL II 536, Aurelius Dorus, en Emerita; TC nota 30, Aurelius Rufus en Cárquere (Viseu); JJX 40, Aurelius VNCI $f$ y ZZ 2, Aurelius en Hinojosa de Duero (Salamanca); EEN 11, Q. Aurelius? en Avela. En Bética: CIL II 2260, Aurelia Valeriana, y CIL II(2).7,422, M. Aurelius Marcellinus, ambos en Corduba; SR 17, Aurelius Celerinianus también en Corduba; AAÑ $311, M$. Aurelius (-) y su hijo M. Aurelius Nympho en llipa; CIL II 1291, G. Aurelius Ampliatus en el territorio de Salpensa; CIL II 6338D, M. Aurelius Castor en Nabrissa; AAÑ 53, Aurelius Hermes en Hispalis; CG 90, Aurelia Afrodisia y su contubernalis Aurelius Myrismus en Italica; AAÑ 267, M. Aurelius Cemerus en Arva. Por otro lado, propiamente en el siglo III ubicamos a TR 50-51, los Aurelii Heraclae, padre e hijo, propietarios de figlinae en las provincias de Córdoba y Sevilla; CIL II(2).5,860-861, L. Aurelius Thebais y Aurelia Agatho, CIL II(2).5,870. Aurelius Carus, todos en Teba (Málaga); CIL II(2).5,375, M. Aurelius Achaicus en Iponoba; CIL II 5528, Aurelia [-- ] en Corduba; AAÑ 222, Aurelius Manus, hijo de Aurelius Pacatianus, rico comerciante de Arva; CG 91, Aurelia Salutaris en Italica; ZJ 1, Aurelius Ugaiddillus y su hermano Musicus también en Italica; CIL II(2).7, 422, Aurelius Marcellinus en Iliturgi. También en el siglo III tenemos dos individuos que podrian ser de origen oriental, AE 1984, 503, Aurelius Polyticus en Italica y CIL II 5521, Aurelius Stephanus en Corduba. En todo caso, abundan en ellos los cognomina griegos, no tienen que ser fruto de una promoción de Caracalla.

103 En Bética podrian ser los casos de AAÑ 222, Aurelius Pacatianus y su hijo Aurelius Manus, y de AAÑ 267, M. Aurelius Cemerus, en Arva, y de ZJ 1, Aurelius Ugaiddillus y su hermano Musicus en Italica, documentos fechados en el siglo 111 en los que concurre además la presencia de cognomina indigenas, aunque también podria tratarse, en los tres últimos, de individuos de origen servil. En Lusitania parece ser el caso de AE 1972, 237, la pareja formada por Aurelia Sotira y Aurelius Donatus, pero serian extranjeros en la provincia, comerciantes de origen dáimata; quizá, TC nota 30, Aurelius Rufus en Cárquere (Viseu), CIL II 368, Aurelius Musaeus y su hijo Aurelius Rufinus en Aeminium; ClL II 536, Aurelius Dorus en Ernerita; RE 44, M. Aurelius Laberianus y su hijo $M$. Aurelius Avitus en Conimbriga, aunque éstos últimos también podrían haber accedido a la ciudadanía bajo el reinado de Marco Aurelio.

${ }_{104}$ Recuérdese la popularidad del praenomen M(arcus) entre los Aurelii portadores de tria nomina en Bética y Lusitania.

105 H. Gallego Franco, «Los Aurelii en Hispania Tarraconense. Un estudio de las fuentes epigráficas", HAnt, XXIV, 2000 (en prensa), en esta provincia algo más de una cuarta parte (29\%) 
popularidad que esta medida dió al nombre Aurelius en el Imperio, así como su aparición con alguna frecuencia en las nuevas élites administrativas y burocráticas bajoimperiales, como ya hemos puesto de manifiesto en el caso de Hispania, se refleje en la notable supervivencia epigráfica del gentilicio en la Antigüedad Tardía ${ }^{106}$, cuando los tradicionales esquemas onomásticos quedan ya vacíos de su antiguo significado jurídico.

\footnotetext{
de los Aurelii parece acceder a la ciudadanía gracias al edicto de Caracalla, tratándose en este caso de individuos del centro-norte y noroeste peninsular en los que su condición de indigenas romanizados se hace especialmente patente a través de restos de onomástica prerromana y en la pervivencia de cultos indigenas, vestigios que no podemos considerar abundantes en la gens pero si altamente significativos.

106 Así, en Lusitania, CIL II 191, Aurelius Firmus en Olisipo, a comienzos del siglo IV; MGI, 40, Aurelia Licinia Florida, en un epigrafe paleocristiano de Emerita; En Bética, CCG p.455, Aurelius Felix Ingenuus en Gades, a finales del siglo IV o principios del siglo V; AV pág. 155, Aurelius Felix en Corduba, mediados del siglo IV o comienzos del siglo $\vee$ d.C.; también en Corduba CIL II 4976.40, Aurelius Vincentius y CIL II 5528, Aurelius/a, en un fragmento paleocristiano; AAÑ 142, Aurelia Proba, en Hispalis, en el siglo v; CIL II(2).5,332, Aurelius Carisius en Igabrum, en los siglos Iv-v d.C.; CIL II(2).5,166, Aurilius-sic en un documento cristiano de Tucci. También en Malacia MG pág. 248, Aurelius lulianus, en el siglo iv d.C, aunque es un extranjero en la provincia, de origen africano. También en la Tarraconense el gentilicio está bien atestiguado en el siglo iv, especialmente en la capital, Tarraco: G. Alfölfy. Die romischen..., 901 Aurelia Paulina y Aurelia Purpuris, 961 Aurelia Tonneia, 959 Aurelia Aemilia Perestera, 960 Aurelia Euthemius-sic; También en Tarraco, HEp 5, 773, Aurelius lanuarius. M.A. Rabanat/J.M. Abascal, "Inscripciones romanas de la provincia de Alicante", Lucentum, IV, 1985, 18, Aurelius en Lucentum.
} 







\begin{tabular}{|c|c|c|c|c|c|c|c|c|c|c|c|c|c|c|c|c|c|c|c|c|}
\hline  & 焉 & 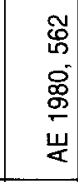 & 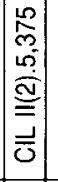 & 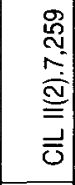 & $\begin{array}{c}\bar{S} \\
\stackrel{2}{ \pm} \\
= \\
\overline{0}\end{array}$ & 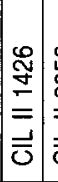 & 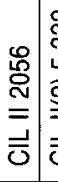 & 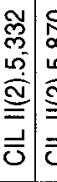 & 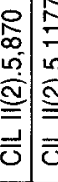 & 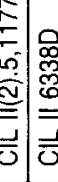 & $=$ & $\mid \begin{array}{l}0 \\
\mathbb{N} \\
2 \\
3 \\
2\end{array}$ & 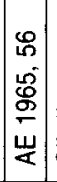 & 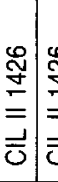 & 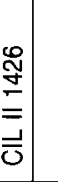 & $\begin{array}{l}\overline{\underline{n}} \\
\underline{x} \\
\tilde{w}\end{array}$ & 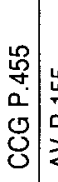 & $\begin{array}{l}\frac{L}{\circ} \\
\frac{0}{2} \\
\gtrless\end{array}$ & 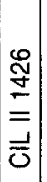 & $\begin{array}{l}\stackrel{g}{0} \\
\stackrel{1}{\infty} \\
\mathbb{\infty} \\
\mathbb{1}\end{array}$ \\
\hline 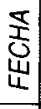 & $\begin{array}{l}\overline{\overline{0}} \\
\frac{\bar{亠}}{\overline{\bar{U}}}\end{array}$ & $\overline{0}$ & $\equiv$ & $\overline{\bar{\Sigma}}$ & \begin{tabular}{|l}
$\overline{\overline{0}}$ \\
$\stackrel{\overline{\bar{u}}}{\mathrm{u}}$ \\
\end{tabular} & $=$ & $\bar{\Sigma}$ & $\begin{array}{l}3 \\
\geq \\
\end{array}$ & $\overline{\overline{0}}=$ & 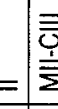 & $\begin{array}{l}\overline{\overline{0}} \\
\frac{\overline{0}}{\overline{4}} \\
\overline{\frac{1}{4}}\end{array}$ & $\frac{\bar{O}}{\frac{1}{\bar{U}}}$ & $=$ & $==$ & $=$ & $=$ &  & $\begin{array}{l}\overrightarrow{0} \\
\dot{1} \\
\dot{\Sigma}\end{array}$ & $=$ & $\stackrel{\equiv}{\equiv}$ \\
\hline 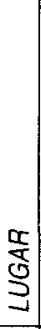 & 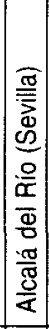 & 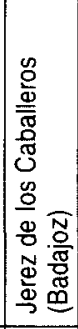 & 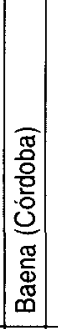 & $\begin{array}{l}\frac{\pi}{0} \\
\frac{0}{8} \\
.0 \\
0\end{array}$ & 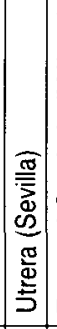 & 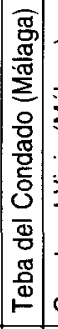 & 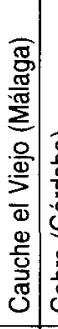 & 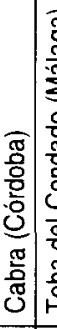 & 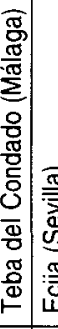 & 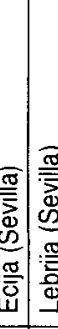 &  & 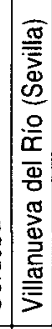 & 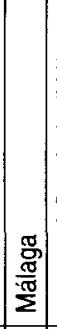 & 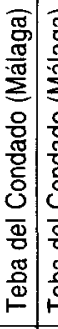 &  &  & 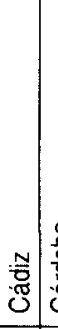 & 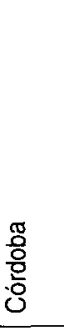 & 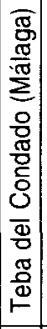 & 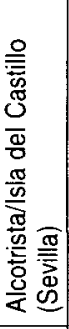 \\
\hline 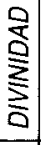 & & & & & 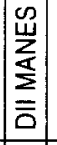 & & & & & & & & & & & 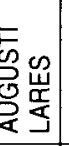 & & & & \\
\hline $\begin{array}{l}\frac{1}{\pi} \\
0 \\
0 \\
5 \\
0 \\
\frac{\pi}{0} \\
\end{array}$ & & 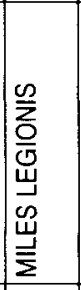 & 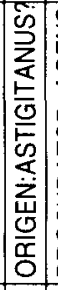 & 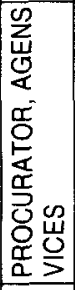 & & & & $\begin{array}{l}\frac{\square}{\vdots} \\
\frac{0}{4} \\
\frac{1}{0} \\
\end{array}$ & & $\frac{\frac{\pi}{2}}{\frac{2}{4}}$ & & & & & & &  & & &  \\
\hline$\frac{\substack{P \\
\frac{5}{\infty}}}{2}$ & & - & $\Xi$ & $\omega$ & & - & & & & & & & & -1 & - & & - & & - & \\
\hline$\frac{\vec{m}}{\mathbb{v}}$ & & $\overrightarrow{\mathbb{S}}$ & & & & & & & & & & & $\overrightarrow{\mathbb{\sigma}}$ & & & & & & & \\
\hline  & $I$ &  &  &  & 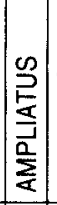 & 号 &  &  & 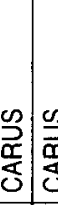 &  &  & 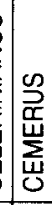 & $\frac{0}{\frac{0}{\pi}}$ & 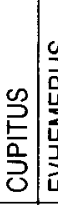 & 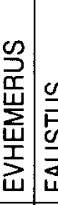 &  &  & 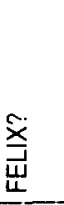 &  & 悹 \\
\hline  & 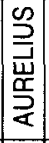 & 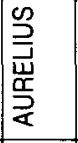 & 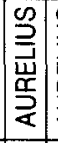 & 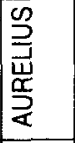 & 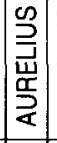 & 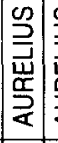 & 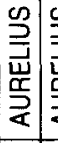 & 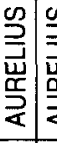 & 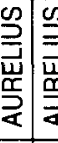 & 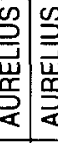 & 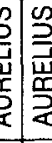 & 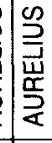 & 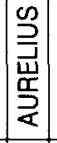 & 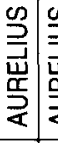 & 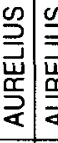 &  & 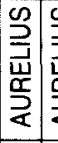 &  &  & 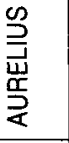 \\
\hline$\frac{r}{2}$ & $\sum$ & $\Sigma$ & $\Sigma$ & $\Sigma$ & $\infty$ & & $-i$ & & & $z$ & $\Sigma$ & $\Sigma$ & $\dot{0}$ & & & 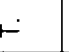 & & & & نـ \\
\hline
\end{tabular}




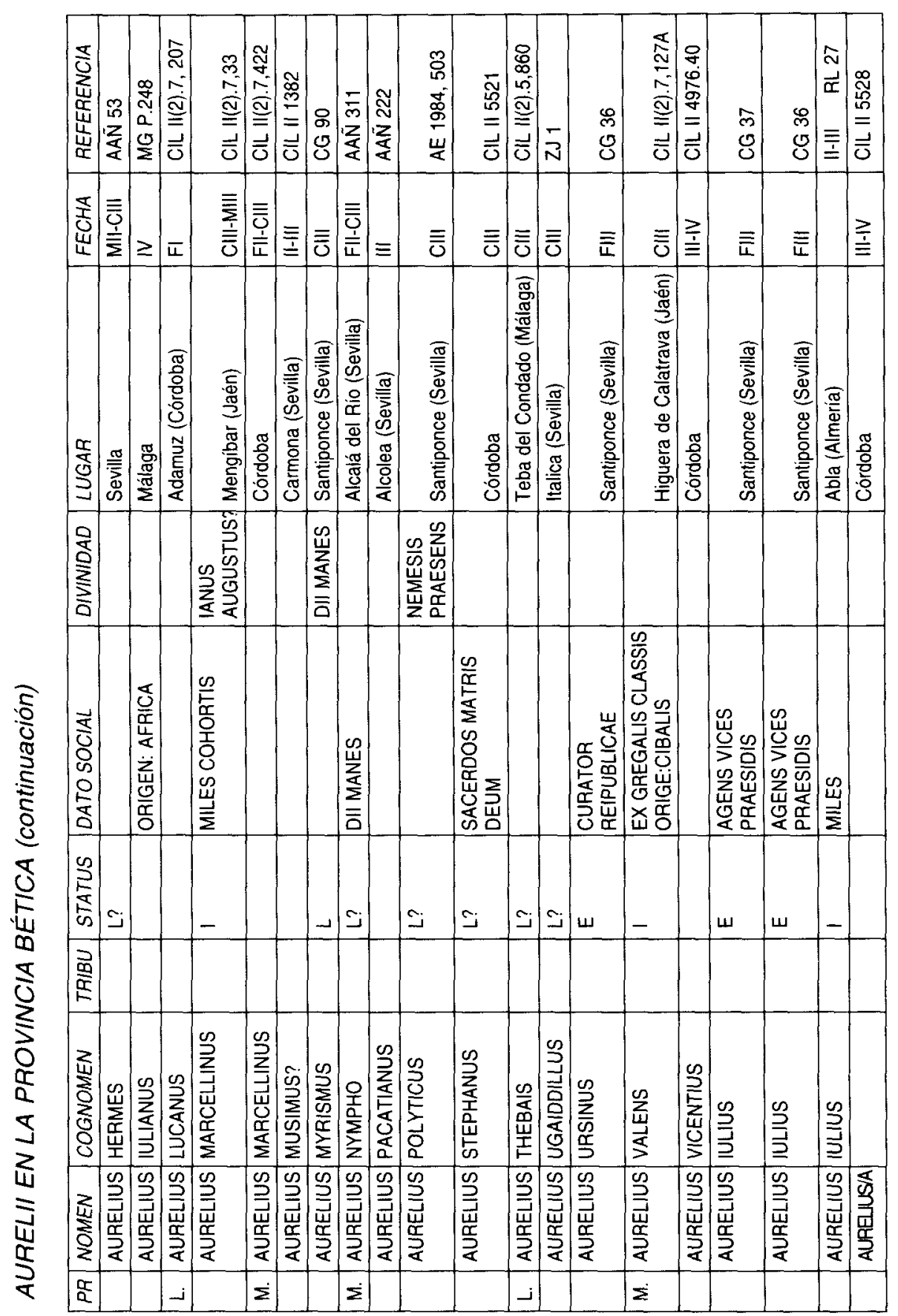




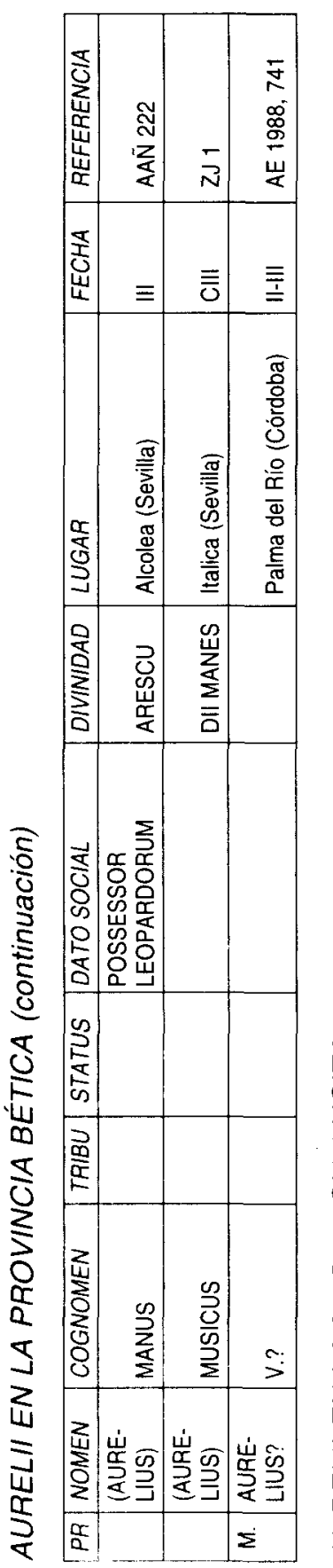

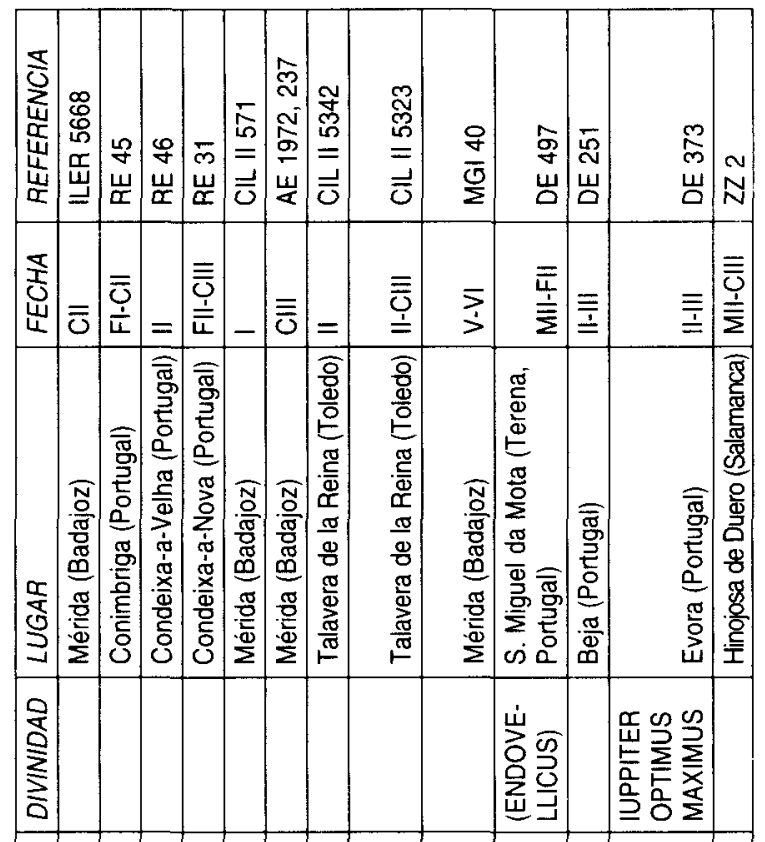

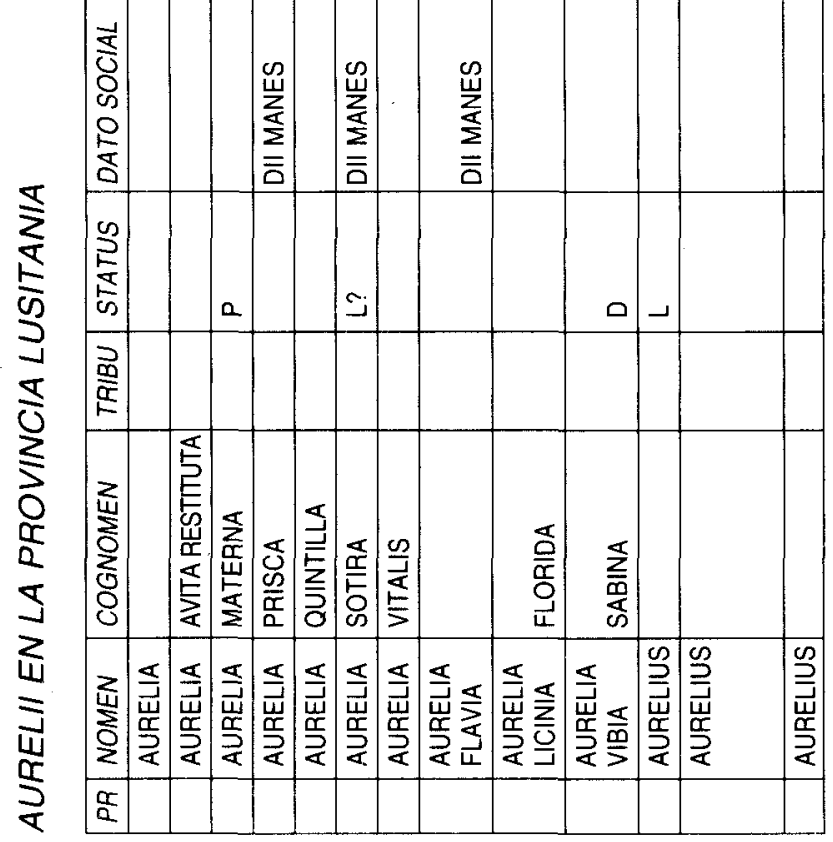




\begin{tabular}{|c|c|c|c|c|c|c|c|c|c|c|c|c|c|c|c|c|c|c|c|c|c|}
\hline$\underset{\widetilde{I}}{\bar{\alpha}}$ & $\begin{array}{l}O \\
\frac{x}{3}\end{array}$ & $\begin{array}{l}0 \\
\tilde{N} \\
w \\
\omega \\
\end{array}$ & $\begin{array}{l}\overline{5} \\
\stackrel{5}{0} \\
w\end{array}$ & $\begin{array}{l}\text { 导 } \\
\text { 㟧 }\end{array}$ & $\begin{array}{l}\mathscr{D} \\
\text { 㟧 } \\
\text { on }\end{array}$ & 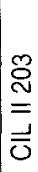 & 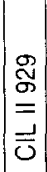 & $\begin{array}{l}\omega \\
\infty \\
0 \\
\Psi \\
\Psi\end{array}$ & 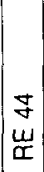 & $\begin{array}{l}\widetilde{Y} \\
\text { N } \\
= \\
\bar{J}\end{array}$ & 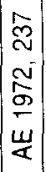 & $\left|\begin{array}{c}0 \\
0 \\
0 \\
= \\
\\
\end{array}\right|$ & $\stackrel{\mathscr{D}}{\stackrel{\equiv}{\equiv}}$ & 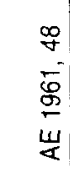 & $\begin{array}{l}\bar{\sigma} \\
\overline{\bar{\sigma}} \\
\overline{\overline{0}}\end{array}$ & 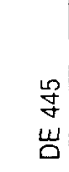 & 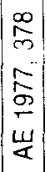 & 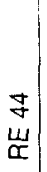 & $\mid \begin{array}{c}\stackrel{8}{0} \\
= \\
\bar{D}\end{array}$ & $\begin{array}{l}\infty \\
\stackrel{0}{0} \\
= \\
\\
\\
\end{array}$ & $\begin{array}{l}\text { 导 } \\
\text { 岩 }\end{array}$ \\
\hline 恋 & $\mid \begin{array}{l}\overline{\overline{0}} \\
\frac{1}{\bar{\Sigma}} \\
\text {. }\end{array}$ & - & $\stackrel{\equiv}{\equiv}$ & - & - & $\overline{\bar{Y}}$ & $\overline{\bar{\Xi}}$ & $\overline{\bar{\Sigma}}$ & $\begin{array}{l}\overline{\overline{\bar{U}}} \\
\overline{\overline{\mathbf{u}}}\end{array}$ & $=$ & $\overline{\overline{\bar{J}}}$ & $\frac{\overline{\bar{c}}}{\frac{\dot{亠}}{\bar{U}}}$ & $\overline{\bar{u}}$ & $\frac{\bar{\equiv}}{\overline{\overline{\bar{u}}}}$ & $\frac{Z}{0}$ & - & $\frac{\overline{\bar{U}}}{\frac{1}{U}}$ & $\mid$\begin{tabular}{|l}
$\overline{\bar{u}}$ \\
$\frac{\vdots}{\overline{\bar{u}}}$ \\
\end{tabular} & $\overline{\bar{U}}$ & $\begin{array}{l}\overline{\bar{U}} \\
\frac{\dot{\bar{u}}}{4}\end{array}$ & - \\
\hline 品 & 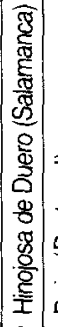 & 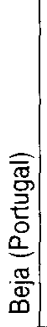 & 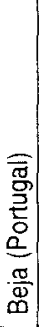 & 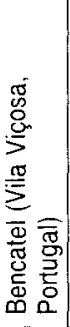 & 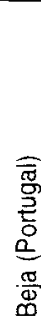 & 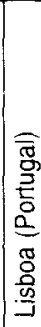 & 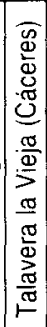 & 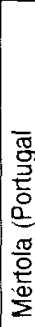 & 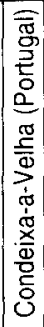 & 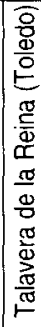 & 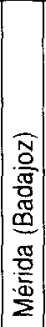 & 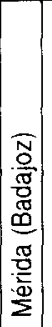 & 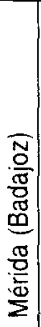 & 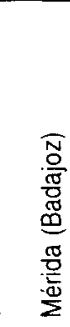 & 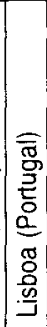 & 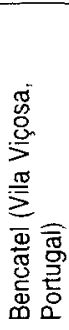 & 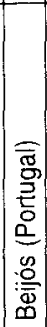 & 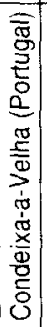 & 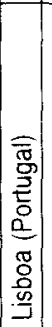 & $\begin{array}{l}\widehat{\bar{\sigma}} \\
\frac{0}{3} \\
0 \\
0 \\
0 \\
\frac{\pi}{0} \\
\frac{0}{0} \\
0\end{array}$ & 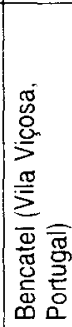 \\
\hline 宊 & & & & & & & & & & $\frac{⿱ u}{2}$ & 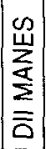 & 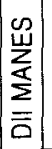 & & $\begin{array}{l}\frac{\omega}{\omega} \frac{\omega}{\omega} \\
\frac{w}{w} \\
\frac{w}{\delta}\end{array}$ & & & & $\frac{\infty}{\frac{w}{2}}$ & & & \\
\hline
\end{tabular}

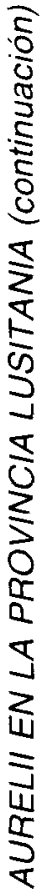

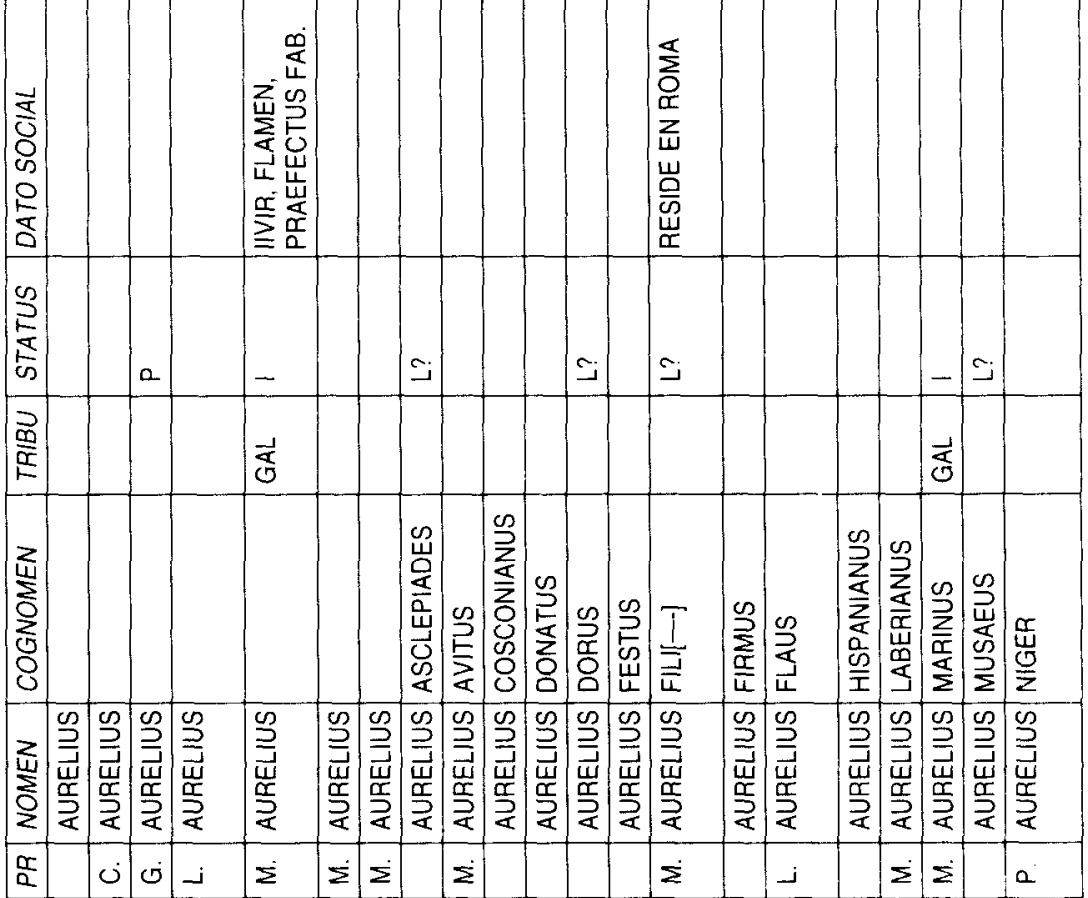




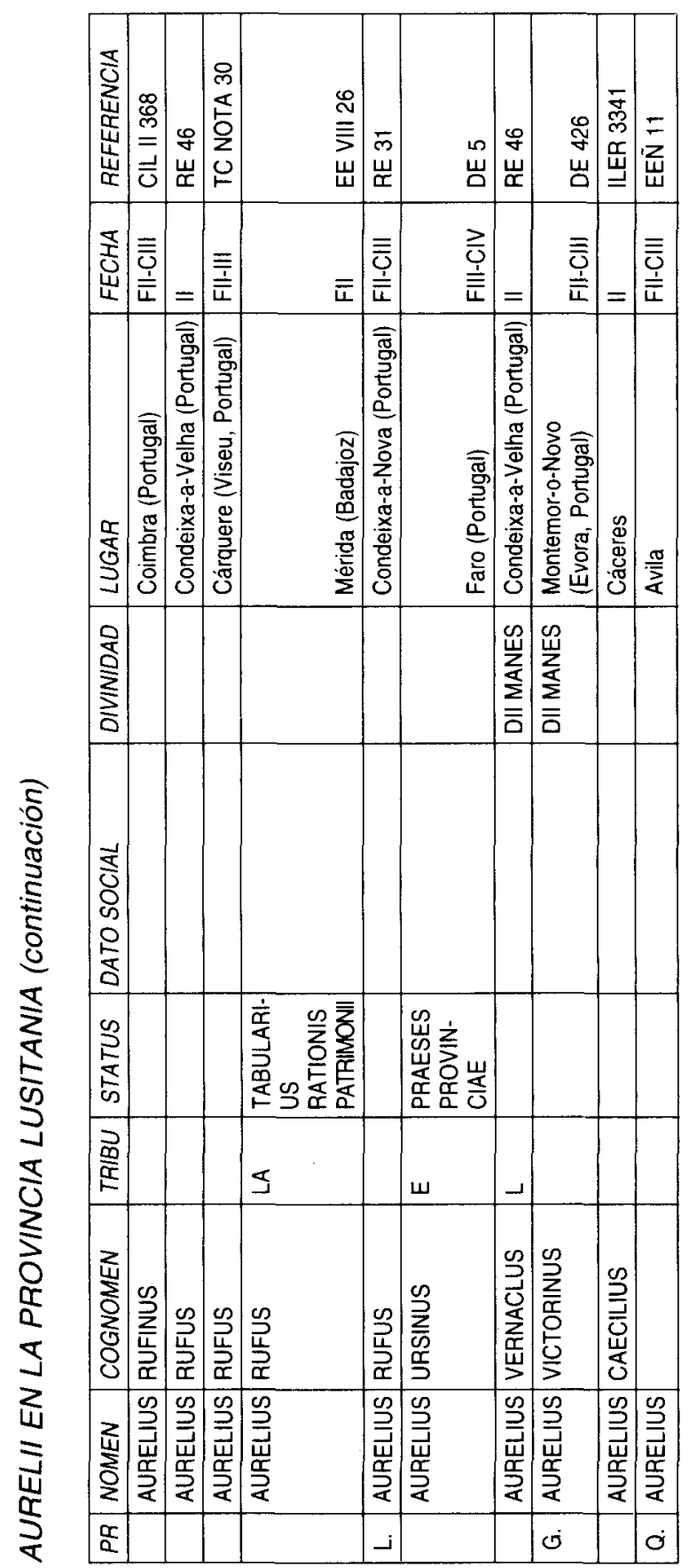




\section{BIBLIOGRAFIA CITADA DE FORMA ABREVIADA}

AAÑ: J. Gonzalez fernández, Corpus de inscripciones latinas de Andalucia. 1. La Vega. Hispalis, Sevilla, 1991.

AE: Année Épigraphique, Paris, 1900-1995

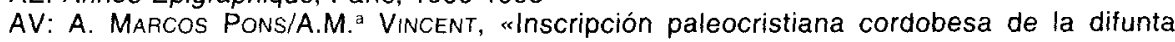
Victoria», Corduba, II, 6, 1977, fasc.3, 153-176.

CCG: F.J. PResedo Velo, "La decadencia de Carteia", Habis, 18-19, 1987-88, 445-458.

CIL II: Corpus Inscriptionum Latinarum, vol. II y suppl.

CIL II(2): Corpus inscriptionum latinarum, vol.ll (edición revisada).

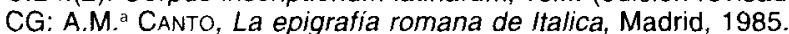

DE: J. D'Encarnaçao, inscriçoes romanas do Conventus Pacensis, Coimbra, 1984.

EE: Ephemeris Epigraphica, vol.VIII y IX.

EEÑ: R.C. Knapp, Latin Inscriptions from Central Spain, Berkeley, 1992.

HEp: Hispania Epigraphica, Departamento de Historia Antigua. Universidad Complutense. Madrid.

ILER: J. VIVES, Inscripciones Latinas de la España Romana, Barcelona, 1972.

JJO: C. Gonzalez Roman/J. Mangas, Epigrafia romana de la provincia de Jaén, I y II, Sevilla, 1991.

JJX: A. JimÉNEZ/L. HERnANoEZ/T. MAÑANES, "Contribución a la epigrafía del oeste de la provincia de Salamanca. El conjunto de Medina del Campo (Valiadolid)», ETF 6, 1993, 133-160.

MG: P. Rodriguez Oliva, "Dos testimonios epigráficos de los contactos entre Malaca y los territorios norteafricanos", Mainake, IV-V, 1982-1983, 243-250.

MGI: M. ${ }^{2}$.T. Garcia ITURRosouE, Tradición, fórmula y literatura en los epitafios latinos de la Hispania Cristiana, Vitoria, 1995.

RE: R. Etienne/G. Fabre/P.et M. Leveque, Fouilles de Conimbriga. II. Epigraphie et sculpture, Paris, 1976.

RL: R. LAZARO, Inscripciones romanas de Almería, Almería, 1980.

SR: E. Serrano/R. ATEnCIA, Inscripciones latinas del Museo de Málaga, Madrid, 1981.

TC: M.M. Alves DIAS, "Antroponimia de Carquere, Resende, Viseu (Lusitania portuguesa)", Studia Paleohispanica, IV, Coloquio de lenguas y culturas paleohispanicas, Veleia 2-3, 1987, 195-203.

TR: G. ChIC GARCiA, Epigrafía anfórica bética, I, Sevilla, 1985.

ZJ: A. CABALlOS, "Varia funeraria italicense", Habis, 25, 1994, 225-245.

ZZ: M. C. SEVILANO, "Nuevas estelas funerarias en Hinojosa de Duero (Salamanca)", Salamanca. Revista Provincial de Estudios, 14, 1984, 172-175, n. 2.

\section{MAPA: DISTRIBUCIÓN TERRITORIAL DE LOS EPIGRAFES DE LA GENS AURELIA EN HISPANIA ULTERIOR}

\section{BÉTICA}

1. Abla Almeria)

2. liturgi (Mengibar, Jaén)

3. Tucci (Martos, Jaén)

4. Iponoba (Baena, Córdoba)

5. Igabrum (Cabra, Córdoba)

6. Higuera de Calatrava (territorio de

7. Adamuz (territorio de Sacili/Alcorrucén,

8. Corduba (Córdoba)

9. Malaca (Málaga)

10. Aratispi (Cauche el Viejo, Málaga)

11. Teba del Condado (Málaga)

12. Sabora (Cañete la Real, Málaga)

13. Astigi (Écija, Sevilla) (incluido Alcotrista y El Portillo, en su territorio)

\section{LUSITANIA}

28. Emerita Augusta (Mérida, Badajoz)

29. Norba Caesarina (Cáceres)

30. Talavera la Vieja (Cáceres) (territorio de Caesarobriga?)

31. Caesarobriga (Talavera de la Reina, Toledo)

32. Avela (Ávila)

33. Hinojosa de Duero (Salamanca)

34. Beijós (Carregal do Sal, Viseu, Portugal)

35. Cárquere (Viseu, Portugal)

36. Aeminium (Coimbra, Portugal)

37. Conimbriga (incluye Condeixa-a-Velha y Condeixa-a-Nova, Portugal)

38. Bencatel (Vila Viçosa, Portugal) 
14. Palma del Río (Córdoba) (territorio de Astigi)

15. Arva (Alcolea, Sevilla)

16. Villanueva del Río (Sevilla) (territorio de Arva)

17. llipa (Alcalá del Río, Sevilla)

18. Italica (Santiponce, Sevilla)

19. Hispalis (Sevilla)

20. Carmo (Carmona, Sevilla)

21. Marchena (Sevilla)

22. Utrera (Sevilla) (procedente de Salpensa?)

23. Nabrissa (Lebrija, Sevilla)

24. Gades (Cádiz)

25. Messangil (Serpa, Portugal)

26. Ficalho (Portugal) (territorio de Arucci/Aroche, Huelva)

27. Jerez de los Caballeros (Badajoz) (territorio de Nertobriga)

39. S. Miguel da Mota (Terena, Portugal)

40. Ebora (Evora, Portugal)

41. Olisipo (Lisboa, Portugal)

42. Pax lulia (Beja, Portugal)

43. Myrtilis (Mértola, Portugal)

44. Ossonoba (Faro, Portugal) 


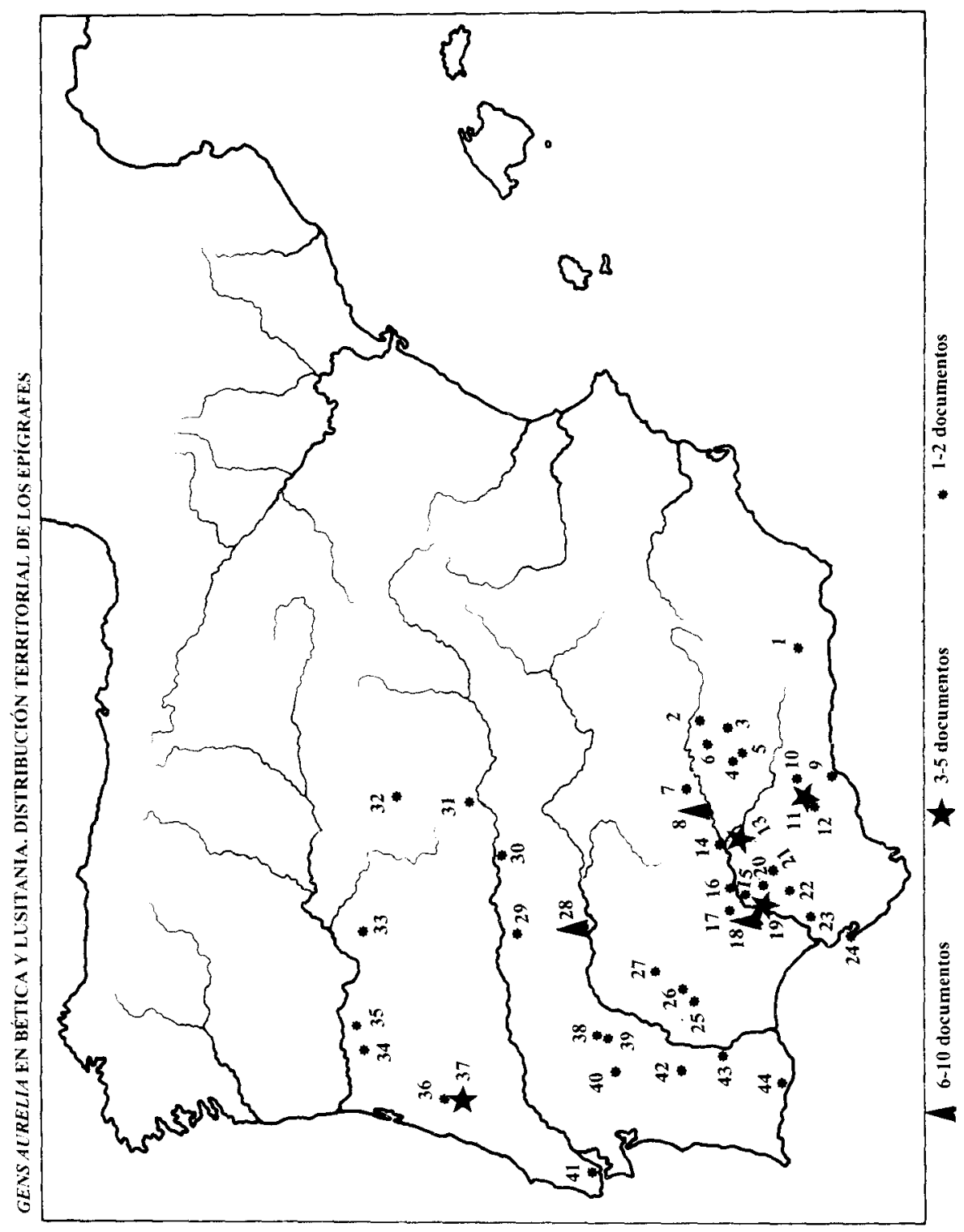

